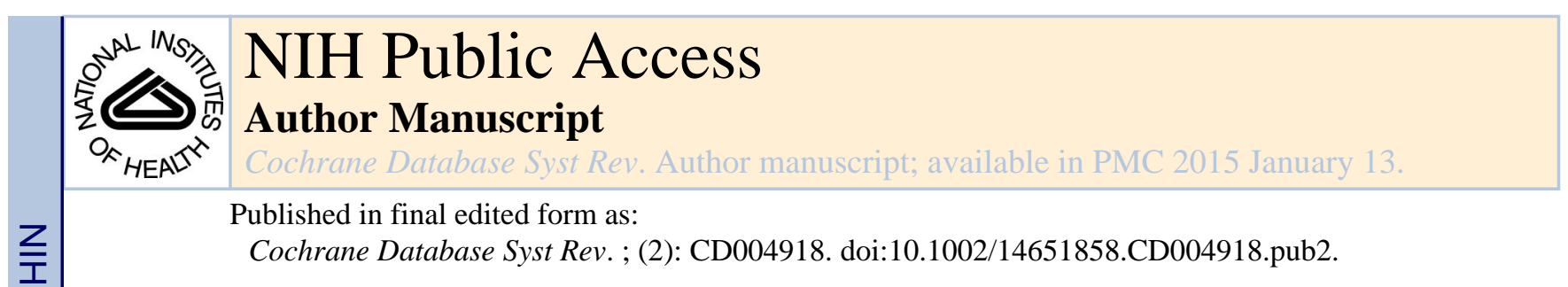

\title{
Aqueous shunts for glaucoma
}

Don Minckler ${ }^{1}$, Satyanarayana S Vedula², Tianjing Li ${ }^{2}$, Milan Mathew ${ }^{3}$, Ramesh Ayyala ${ }^{4}$, and Brian Francis ${ }^{5}$

${ }^{1}$ Department of Ophthalmology, University of California, Irvine, Irvine, CA, USA

${ }^{2}$ Cochrane Eyes and Vision Group US Project, Johns Hopkins Bloomberg School of Public Health, Baltimore, MD, USA

${ }^{3}$ Memorial Hospital of Rhode Island, Pawtucket, USA

${ }^{4}$ Department of Ophthalmology, Tulane University School of Medicine, New Orleans, USA

${ }^{5}$ Los Angeles, USA

\section{Abstract}

Background-Aqueous shunts are employed for intraocular pressure (IOP) control in primary and secondary glaucomas that fail medical, laser, and other surgical therapies.

Objectives-This review compares aqueous shunts for IOP control and safety.

Search strategy-We searched CENTRAL, MEDLINE, PubMed, EMBASE, NRR in January 2006, LILACS to February 2004 and reference lists of included trials.

Selection criteria-We included all randomized and quasi-randomized trials in which one arm of the study involved shunts.

Copyright @ 2009 The Cochrane Collaboration. Published by John Wiley \& Sons, Ltd.

Contact address: Don Minckler, Department of Ophthalmology, University of California, Irvine, 118 Med Surge I, Irvine, CA, 92697-4375, USA. minckler@uci.edu.

* Indicates the major publication for the study

Contributions of Authors: Conceiving the review: DM

Designing the review: DM, MM

Coordinating the review: DM, SSV, MM

Screening search results: DM, MM, SSV, TJL

Organizing retrieval of papers: SSV, MM

Screening retrieved papers against inclusion criteria: DM, MM, SSV, TJL

Appraising quality of papers: DM, RSA, BAF, SSV, TJL, MM

Extracting data from papers: DM, SSV

Writing to authors for additional information: SSV, DM

Providing additional data about papers: DM, SSV

Obtaining and screening data on unpublished studies: DM

Data management for the review: SSV, DM

Entering data into RevMan: SSV, TJL

Analysis of data: DM, SSV

Interpretation of data: DM, SSV

Writing the review: DM, SSV

Securing funding for the review: DM, SSV

Performing previous work that was the foundation of current study: DM

Declarations of Interest: None known. Although Allergan has provided a grant to USC-Doheny, this is solely for teaching purposes. Allergan does not manufacture aqueous shunts. 
Data collection and analysis-Two authors independently extracted data for included studies and a third adjudicated discrepancies. We contacted investigators for missing information. We used fixed-effect models and summarized continuous outcomes using mean differences.

Main results-We included fifteen trials with a total of 1153 participants with mixed diagnoses. Five studies reported details sufficient to verify the method of randomization but only two had adequate allocation concealment. Data collection and follow-up times were variable.

Meta-analysis of two trials comparing Ahmed implant with trabeculectomy found trabeculectomy resulted in lower mean IOPs 11 to 13 months later (mean difference $3.81 \mathrm{~mm} \mathrm{Hg}, 95 \%$ CI 1.94 to $5.69 \mathrm{~mm} \mathrm{Hg}$ ). Meta-analysis of two trials comparing double-plate Molteno implant with the Schocket shunt was not done due to substantial heterogeneity. One study comparing ridged with standard double-plate Molteno implants found no clinically significant differences in outcome. Two trials investigating the effectiveness of adjunctive mitomycin (MMC) with the Molteno and Ahmed implants found no evidence of benefit with MMC. Two trials that investigated surgical technique variations with the Ahmed found no benefit with partial tube ligation or excision of Tenon's capsule. One study concluded there were outcome advantages with a double versus a single-plate Molteno implant and one trial comparing the $350 \mathrm{~mm}^{2}$ and $500 \mathrm{~mm}^{2}$ Baerveldt shunts found no clinically significant advantage of the larger device but neither of these trials included all patients randomized. One study suggested improved clinical outcome when MMC was employed with a newly described shunt including ultrasound supporting the conclusion. One small study did not demonstrate an outcome advantage to systemic steroid use postoperatively with single-plate Molteno shunts. One study comparing endocyclophotocoagulation (ECP) with Ahmed implant in complicated glaucomas found no evidence of better IOP control with Ahmed implant over ECP.

Authors' conclusions-Relatively few randomized trials have been published on aqueous shunts and methodology and data quality among them is poor. To date there is no evidence of superiority of one shunt over another.

\section{Medical Subject Headings (MeSH)}

*Glaucoma Drainage Implants [adverse effects]; *Intraocular Pressure; Cataract Extraction; Glaucoma [* surgery]; Molteno Implants [adverse effects]; Ocular Hypertension [surgery]; Randomized Controlled Trials as Topic; Trabeculectomy

\section{MeSH check words}

Humans

\section{Background}

\section{Introduction}

Aqueous shunts are employed as surgical interventions to control intraocular pressure (IOP) in primary open-angle or secondary angle-closure glaucomas that have failed medical and laser therapies in addition to one or more surgical procedures such as trabeculectomy. The term aqueous shunt is preferred by the American National Standards Institute (ANSI) as most appropriate for the group of devices referred to in current peer reviewed literature as 
glaucoma drainage devices, tube-implants, tube-shunts or in-appropriately as setons, a term that should be reserved for non-lumened devices (ANSI Z80 1998; Minckler 1997).

All the aqueous shunts considered in this review are composed of a lumened silicone rubber tube attached to an explant plate. The Molteno implant, the first successful and widely utilized such device, remains the gold standard commercially available example (Molteno 1981; Molteno 2001; Molteno 2003). Newer shunts, including the Ahmed, Baerveldt, and Krupin, have features in common with the Molteno, but vary in size, shape, composition and the presence or absence of flow-restricting components (Prata 1996). Among these four, all but the Krupin are available with different sized explants. The Ahmed and Molteno devices come in one or two-plate versions. The Ahmed is now available in either rigid (polymethylmethracylate) or flexible (silicone rubber) versions in one or two plate models. The Schocket shunt, assembled intraoperatively, utilizes buckling elements and a segment of silicone rubber tubing. The modified Schocket shunt or anterior chamber tube shunt to an encircling band (ACTSEB) procedure utilizes a previously installed buckle element as the explant to which a segment of tubing is attached. Schocket shunts are essentially equivalent in concept to commercially available devices (Schocket 1982; Sidoti 1994). The surface area of the explant has been demonstrated to correlate with clinical effectiveness in humans (Heuer 1992). No randomized trials utilizing the most recently marketed shunt, the ExPRESS, a translimbal stainless steel tube with an internal diameter of 50 $\mu \mathrm{m}$, have been published (Gandolfi 2002). The OptiMed, White shunt pump, and Joseph implants, are relatively recent in origin, and not in current use. Only sparse details are available regarding the specifications of the Hunan shunt (Duan 2003).

\section{Epidemiology}

Based on informal feedback from manufacturers and US Medicare database information (1995 and 1998), approximately 3000 to 4000 aqueous shunts are utilized per year in the US alone. Aqueous shunts are used in infants and children in addition to adults, but no survey has been done allowing breakdown by glaucoma category, sex or specific age ranges, or safety and effectiveness of the variety of different sized devices available. There are no data that track the utilization patterns of aqueous shunts with regard to age, sex, or race, but it seems likely they will be increasingly applied to complex glaucomas at an earlier stage among patients of all ages and races, especially during combined glaucoma and cataract procedures (Hoffman 2002). Commercially available aqueous shunts cost between $\$ 400$ and $\$ 600$ in the US, not including surgeon fees or other costs associated with surgery.

\section{Indications for use}

The majority of adult eyes in which aqueous shunts are currently used in the US are pseudophakic (contain a lens implant after cataract extraction) (Mills 1996; Minckler 1988). Aqueous shunts also have clinical application to neovascular, post-traumatic, inflammatory glaucomas, and congenital glaucomas that fail goniotomy or trabeculotomy (Djodeyre 2001). Aqueous shunts are used to manage glaucoma in complex cases where penetrating keratoplasty and retina-vitreous surgery may be simultaneously or serially performed (Lloyd 1989). They are generally preferred to cyclodestructive procedures in the US (surgery that destroys part of the ciliary body, cyclocryotherapy or trans-scleral laser) when functional 
central vision (better than 20/100) is present (Chalam 2002), but not in Europe where cyclodestruction is still preferable. Aqueous shunts may be preferable to trabeculectomy with adjunctive anti-fibrotic agents in people who work in dusty or dirty environments or who require contact lenses for functional vision or in those who are immunocompromised, as the risk of late infection is less.

The flow-restricted devices (Ahmed, Krupin, White shunt pump, Joseph implant, OptiMed) have typically been installed in one stage (complete installation) with immediate function. The nonflow-restricted devices (Molteno, Baerveldt) are typically installed in two stages either in two separate operations or with utilization of a variety of temporary flow-restricting techniques. With all of these devices the anterior edge of the explant plate is generally located 8 to $10 \mathrm{~mm}$ posterior to the limbus with the explant centered at the equator (Minckler 1988; Prata 1995a; Prata 1995b). The delay in opening of the non flow-restricted shunts via two-stage operations allows encapsulation to develop over the explant before flow of aqueous humor begins and reduces the risk of hypotony postoperatively. The ExPRESS is currently being marketed as a one-stage device.

\section{Prognosis, complications and alternatives}

Aqueous shunts may prevent or delay blindness and visual disability in a large percentage of people in whom they are used. Comorbidities, including optic nerve injury, corneal disease, or other damage related to past trauma or previous surgery are frequently present in eyes in which shunts are employed. Prospectively, aqueous shunts probably increase the risk of endothelial failure and they are widely thought to increase the risk of graft failure after penetrating keratoplasty, especially with the drainage tube installed in the anterior chamber.

The long-term outcome (success and persistence of benefit) for aqueous shunts has not been well studied, but some reports indicate that IOP control benefits may extend for several decades (Molteno 2001; Molteno 2003). In general, the failure rates per year parallel those of trabeculectomy in similar cases (FFSSG 1996). The principal long-term complication of anterior chamber aqueous shunts is corneal endothelial decompensation. Other postoperative problems include transient hypotony, probably due to leak around the tube in limbal tissues or failure of flow-restricting devices to maintain sufficient resistance. Additionally, several reports have described a postoperative hypertensive phase, probably due to inflammation induced by flow of aqueous humor around the explant, necessitating resumption of topical anti-glaucoma medications for many weeks. Clinical failure in many cases is due to excessive fibrosis and relative impermeability of the capsule around the explant.

The current standard initial surgical procedure for glaucoma is trabeculectomy. In some locales, non-penetrating filtering procedures, either viscocanalostomy or deep sclerectomy would be the first alternative before trabeculectomy and before aqueous shunts. Aqueous shunts are currently the standard of care in the US for complicated glaucomas, especially pseudophakic eyes that have failed one or more previous trabeculectomies.

\section{Rationale for systematic review}

Recently published retrospective case series have indicated long-term benefit from aqueous shunts in pseudophakic, inflammatory, and traumatic glaucomas (Molteno 2001; Molteno 
2003). However, there has been no review of randomized trials as to the effectiveness and safety of aqueous shunts as surgical therapy for glaucomas. Controversy persists regarding when aqueous shunts should be used in the sequence of glaucoma surgeries as well as the effectiveness of different aqueous shunts. Most US surgeons reserve aqueous shunts until one or more standard procedures have failed. The use of aqueous shunts in combined cataract and glaucoma surgeries has received relatively little attention and no randomized trials investigating this issue have been identified (Hoffman 2002). Only two published randomized trials (Wilson 2000; Wilson 2003) have compared a shunt (Ahmed) with trabeculectomy and only the latter included previously un-operated eyes. Virtually all previously published case series have described the utilization of shunts in eyes after previous failed standard filtering surgery. A new study currently in progress, the Tube versus Trabeculectomy Study centered at Bascom Palmer Eye Institute in Miami Florida, is comparing Baerveldt shunts with trabeculectomy in phakic and pseudophakic eyes after previous cataract or filtering surgery, or both (Gedde 2005).

\section{Objectives}

The objective of this review was to assess the safety and effectiveness of aqueous shunts for reducing IOP in glaucoma.

\section{Methods}

\section{Criteria for considering studies for this review}

Types of studies-Only randomized and quasi-randomized trials were included.

Types of participants-We included trials in which the participants were diagnosed with glaucoma irrespective of their lens status. There were no restrictions with regard to patient age, gender, ethnicity, co-morbidities, use of adjunctive medications or the numbers of participants.

Types of interventions-All trials that compared various aqueous shunts with standard surgery or cyclodestruction or to each other were included. We also included trials that compared different surgical techniques and use or non-use of adjunctive mitomycin $\mathrm{C}$ or corticosteroids with specific shunts.

\section{Types of outcome measures}

\section{Primary outcomes}

1. Control of IOP assessed as:

a. mean decrease from baseline (immediate pre-operative IOP) on day one, during weeks one to 12 , six months, one year and as available throughout follow up and at last follow up, measured using Goldmann tonometry, TonoPen, or other standard devices. Mean decrease from baseline at one year was considered as the main primary outcome of the review;

b. dichotomization of data, wherever possible, was attempted using the following definitions for control of IOP: 
- $\quad$ success - a decrease of IOP by $15 \%$ from baseline at 12 months;

- $\quad$ complete success - IOP $\leq 21 \mathrm{~mm} \mathrm{Hg}$ on no adjunctive medications at 12 months;

- $\quad$ qualified success - IOP $\leq 21 \mathrm{~mm} \mathrm{Hg}$ on medications at 12 months;

- failure - IOP > $21 \mathrm{~mm} \mathrm{Hg}$ on or off medications at 12 months or complete loss of vision or performance of additional surgery or loss of the eye.

\section{Secondary outcomes}

1. Visual acuity was considered stable if unchanged or within one line of letters of baseline measurements (Snellen; ETDTRS; logMAR) at last follow up. Decreased vision was defined as loss of two or more lines or 10 or more letters compared with baseline using the same measuring methods at last follow up.

2. The duration (weeks) of a recognizable postoperative hypertensive phase (more than $5 \mathrm{~mm} \mathrm{Hg}$ elevation of IOP above baseline levels).

3. The follow-up interval required to reach a $15 \%$ reduction from baseline IOP in weeks and the duration of this effect (months-years) attributable to the shunt through last follow up.

4. Visual field as available throughout follow up and at last follow up as measured by any method.

5. Total number of anti-glaucoma medications, both topical and systemic, as adjuncts to surgery at variable lengths of follow up.

Complications-Complications were tabulated as adverse events during the duration of follow up for all trials. Data was too sparse and inconsistently recorded to stratify all complications as intraoperative or by time postoperatively although some 'late' complications were reported. Adverse effects of interest included but were not limited to:

- $\quad$ corneal injury (endothelial decompensation/edema);

- $\quad$ suprachoroidal hemorrhage;

- $\quad$ retinal detachment;

- $\quad$ cataract;

- hypotony;

- infection;

- $\quad$ strabismus;

- $\quad$ host-immune response to anterior chamber tubes (keratic precipitates);

- $\quad$ clinical failure;

- late hypotony; 
- late wound leaks;

- late failure due to vitreous or fibrin plugging of tubes including pars plana installations in post-vitrectomy eyes.

Quality of life-Data on quality of life available from the included studies were to be summarized.

Follow up: No restrictions were placed on the duration of follow up.

\section{Search methods for identification of studies}

Electronic searches-We identified trials from the Cochrane Central Register of Controlled Trials (CENTRAL) (which contains the Cochrane Eyes and Vision Group Trials Register) in The Cochrane Library (Issue 1, 2006), MEDLINE (1966 to January 2006, week 4), PubMed (31st January 2006, restricted to last 90 days), EMBASE (1980 to 2006, week 4) and Latin American and Caribbean Health Sciences Literature Database (LILACS) (February 2004). The updated searches included the National Research Register (NRR) database (Issue 1, 2006). There were no language or date restrictions in the electronic searches.

See: Appendices for details of search strategies for each database.

Searching other resources-We searched the reference lists of identified trial reports to find additional trials. We used the Science Citation Index to find studies that cited the identified trials. We did not conduct manual searches of conference proceedings or abstracts specifically for this review.

\section{Data collection and analysis}

Assessment of search results-Two authors independently assessed the titles and abstracts of all reports identified by the electronic and manual searches as per the 'Criteria for considering studies for this review'. The abstracts were classified as (a) definitely include, (b) unsure or (c) definitely exclude. Full copies of those classified as (a) definitely include and (b) unsure were obtained and re-assessed. These studies were classified as (1) included, (2) awaiting assessment or (3) excluded. A third author resolved any disagreements. Studies identified as (1) included were assessed for methodological quality. We contacted the primary investigators for clarification of studies classified as (2) awaiting assessment. We excluded studies identified by both authors as (3) excluded. The authors were unmasked to the report authors, institutions and trial results during this assessment.

Assessment of methodological quality-Two authors assessed trials according to methods set out in Section 6 of the Cochrane Handbook for Systematic Reviews of Interventions(Higgins 2005b). We considered the following parameters: method of allocation and concealment of allocation (selection bias), rates of follow up and intention-totreat analysis (attrition bias). Allocation concealment was graded as: (A) adequate; or (B) unclear or not reported; or (C) inadequate. Any method which suggested appropriate concealment of allocation such as centralized randomization, use of opaque, sealed 
envelopes was considered to be adequate. We contacted the primary investigators when the method of allocation concealment was unclear. A third author resolved any disagreement on assessment of quality of the included studies. Masking of investigators during clinical trials comparing aqueous shunts with other methods of glaucoma surgery would not be possible, as the presence of an anterior chamber or vitreous tube or standard filtering bleb would be obvious to any observer. Hence we did not use masking of care providers, participants and outcome assessors as quality criteria for such comparisons in this review.

Assessment of study characteristics-In addition to the parameters described above, we extracted study characteristics such as details of participants, the interventions, the outcomes, and other relevant information.

Data collection-Two authors independently extracted data for the primary and secondary outcomes onto paper data collection forms developed by the Cochrane Eyes and Vision Group. The forms were pilot tested on two trials and the revised form was used to extract data from the included trials. We resolved discrepancies by discussion. We contacted primary investigators for missing data. Wherever possible, and for included trials for which the investigators were unable to provide us with the data, we extracted the same from figures in the published papers. We extracted the mean IOP values where mean change in IOP was not available. Where success in controlling IOP was analyzed using Kaplan-Meier or lifetable analyses, we tried to extract data on log-hazard ratios either through log-rank statistics or through published Kaplan-Meier curves if time points for losses to follow up were mentioned. One author entered data into RevMan 4.2 and this was verified using the double data-entry facility.

Data synthesis-Data analysis followed the guidelines in Section 8 of the Cochrane Handbook for Systematic Reviews of Interventions (Deeks 2005). For dichotomous outcomes we calculated a summary risk ratio. We calculated mean differences for continuous outcomes including mean postoperative IOP, $\log$ MAR visual acuity, and antiglaucoma medications. We tested for statistical heterogeneity using the chi-square test and by examining the I-square value. If no statistical heterogeneity was detected and if there was no clinical heterogeneity within the trials we combined the results in a meta-analysis. We used a fixed-effect model since there were fewer than three trials in the analyses. In case of statistical or clinical heterogeneity we did not combine study results but presented a narrative summary.

It was not possible to perform subgroup analyses according to the type of glaucoma (primary angle-closure; primary open-angle; secondary including neovascular) and the number of previous surgeries as sufficient numbers specifying these parameters were not available due to marked variability in data reporting.

Sensitivity analysis-There were too few studies to conduct sensitivity analyses to examine the impact of exclusion of studies with lower methodological quality as stated in the protocol. We planned to conduct sensitivity analyses by excluding industry-funded trials but none of the included studies reported being funded by industry. 


\section{Results}

\section{Description of studies}

See: Characteristics of included studies; Characteristics of excluded studies; Characteristics of ongoing studies.

Results of the search-The original electronic searches yielded 851 titles and abstracts. Searching the Science Citation Index resulted in an additional 204 titles and abstracts. Out of a total of 1055 titles and abstracts 74 were identified to be relevant. On examining the full text, 16 articles were identified to be eligible for inclusion and 47 studies were excluded. Of the 16 trial reports eligible for inclusion in the review two were reports of the same study at different times of follow up. Thus, we found 15 trials eligible for inclusion in this review. Further clarification was required for 10 studies and these are currently listed as 'Characteristics of studies awaiting classification'.We will update the review with information on these studies as it becomes available.

Included studies-The following is a concise summary of the salient features of the included studies. A detailed description of each trial is presented in the 'Characteristics of included studies' table.

Types of participants: The trials enrolled a total of 1153 participants. These were mostly adult patients from both genders over a wide range of ages, and some children. Wilson 2003 included only patients with primary open-angle and closed-angle glaucoma. Susanna 2003 included only patients with neovascular glaucoma. Participants in the remaining 13 trials had varied diagnoses in terms of the type of glaucoma including primary glaucomas, neovascular glaucoma, uveitic glaucoma, and other forms of secondary glaucomas. The trials also varied in lens status of enrolled participants. None of them excluded patients with aphakia or pseudophakia. None of the studies attempted to stratify patients by disease severity. The trials varied in size with the smallest one enrolling only 17 participants (Hwang 2004) and the largest enrolling 154 participants (Duan 2003).

Types of interventions: The included trials varied widely with regard to the interventions they evaluated. Two trials (Smith 1992; Wilson 1992) compared double-plate Molteno implants with a Schocket shunt (ACTSEB). Two trials (Wilson 2000; Wilson 2003) compared the Ahmed implant with trabeculectomy and adjunct MMC. The interventions compared in the remaining trials included $350 \mathrm{~mm}^{2}$ and $500 \mathrm{~mm}^{2}$ Baerveldt implants; single-plate and double-plate Molteno implants; ridged and standard Molteno implants; use of anti-fibrotic agents such as MMC and corticosteroids; different surgical techniques such as partial resection of Tenon's capsule and partial ligation of the tube with Ahmed implants (Table 1).

Types of outcomes: All but one trial (Kee 2001) considered IOP control as the main outcome. Kee 2001 also compared the incidence of hypotony between experimental and control groups. Eleven trials defined success in IOP control. However, only Wilson 2000 and Wilson 2003 used identical success and failure definitions. None of the trials reviewed used the a priori criteria exactly as stated in the 'Criteria for considering studies for this 
review' section above. Only Wilson 1992 and Valimaki 1999 reported the mean change in IOP from baseline as an outcome. We used final mean IOP values where reported and mean IOP where mean change in IOP was not reported.

Visual fields data were included in only three trials (Duan 2003; Wilson 2000; Wilson 2003). The average number of postoperative medications was reported in all trials except Susanna 2003. Visual acuity measurements were by $\log$ MAR charts, the most standardized method, in four trials (Cantor 1998; Lima 2004; Wilson 2000; Wilson 2003). Duan 2003 utilized an internationally standardized visual acuity chart but did not provide further details regarding the chart. Wilson 1992 measured postoperative acuity as decline in number of Snellen lines from baseline, and Heuer 1992 noted postoperative visions as 'stable' within one line of baseline; 'better' improved by at least two lines from baseline; and 'worse' at least two lines less than baseline. Smith 1992 reported Snellen acuities pre and postoperatively.

The postoperative 'hypertensive phase' was acknowledged and specifically reported only in Susanna 2003 but was discussed in Hwang 2004, Lima 2004 and Smith 1992. Only Wilson 2000 and Wilson 2003 included quantitative data on lens changes after shunts in phakic eyes.

Complications were too variably reported to allow comparative tabulation of intraoperative, early (within the first two days) and late (after two days) or postoperatively throughout follow up. Adverse effects of interest included corneal injury (endothelial decompensation with edema); choroidal effusion; suprachoroidal hemorrhage; retinal detachment; cataract; hypotony, infection, strabismus, host-immune response to anterior chamber tubes (keratic precipitates), postoperative hypertensive phase duration, clinical failure, late hypotony and late wound leaks were also variably reported and could not be compared across devices. Important complications reported in the published papers of the included studies are tabulated in Table 2.

Excluded studies—See 'Characteristics of excluded studies' table for further details.

\section{Risk of bias in included studies}

Overall, the trials included in this review were of low methodological quality. The results of our quality assessment are described in detail in the 'Characteristics of included studies' table. Below is a concise overall summary of the methodological quality of trials included in this review.

The method of randomization was explicitly stated and methodologically adequate in five trials (Britt 1999; Heuer 1992; Wilson 1992; Wilson 2000; Wilson 2003). The method of randomization was not explicitly stated in eight of the 15 included trials. Two trials adopted a method of quasi-randomization, flipping a coin for the first patient and alternating assignment of the remaining patients (Lima 2004; Susanna 2003). Consequently, allocation concealment was not possible in these two trials. The method of allocation concealment was adequate in two trials (Britt 1999; Heuer 1992) and unclear for the remaining included trials. 
Primary investigators whom we were able to contact could not provide us with further information.

Masking of participants and surgeons is not possible with the kind of interventions involved when two different types of aqueous shunts are evaluated. However, masking of surgeons, and sometimes participants, is possible when adjunctive treatments are being evaluated such as adjunctive topical use of MMC with an implant. Of the four trials evaluating adjunctive treatment where masking of the operating surgeon was possible (Cantor 1998, Costa 2004, Duan 2003; Valimaki 1999), Cantor 1998 reported adequate masking of the operating surgeon; masking of the surgeon was not attempted in Costa 2004, Duan 2003 and Valimaki 1999. Masking of investigators measuring the IOP and visual acuity outcomes may be possible but was either not attempted or attempted and not reported in any of the included trials.

There were significant losses to follow up in many of the included trials. We considered a trial to have been analyzed by intention-to-treat only if all patients randomized were included. Only three trials reported an intention-to-treat analysis (Hwang 2004; Lima 2004; Smith 1992).

The unit of randomization in the trials was the patient except for two trials which randomized eyes to the different intervention groups (Gerber 1997; Smith 1992). The unit of randomization was unclear in two trials (Duan 2003; Hwang 2004). The unit of analysis was eyes in all included trials. Four trials randomized both eyes of some of the patients to different intervention groups (Duan 2003; Gerber 1997; Hwang 2004; Smith 1992). Twenty five per cent of participants ( 2 of 8 ) in one group and $10 \%$ in the other had both eyes included in one trial (Hwang 2004). Such a design is methodologically flawed since we may not consider the treatment effect in both eyes to be independent.

\section{Effects of interventions}

All issues evaluated in this review are summarized in Table 1.

\section{Ahmed implant versus trabeculectomy}

Mean intraocular pressure (IOP) at 11 to 13 months follow up (Analysis 1.1): Two studies compared Ahmed implant with trabeculectomy (Wilson 2000; Wilson 2003). We extracted data on mean IOP at 11 to 13 months from figures in the published papers since we were unable to procure from the trial investigators, data on mean change of IOP, the primary outcome for this review. Since the participants in both groups in a randomized trial are similar at baseline due to randomization, comparison of the final mean IOP estimates the same treatment effects as comparison of mean change from baseline values. The chi-square test for heterogeneity did not show statistical significance $(\mathrm{P}=0.14)$ and the I-square value was $53.5 \%$. Using a fixed-effect model we calculated a pooled mean difference of $3.81 \mathrm{~mm}$ $\mathrm{Hg}$ in favor of trabeculectomy (95\% confidence interval (CI) 1.94 to 5.69). The trial investigators reported findings for only about 73\% (Wilson 2000) and 89\% (Wilson 2003) of randomized patients at 11 to 13 months follow up. 


\section{Ahmed implant versus endocyclophotocoagulation (ECP)}

Mean IOP (Analysis 2.1): Seventy nine per cent of participants in Ahmed implant group and $91 \%$ in ECP group were analyzed for mean IOP at 12 months follow up in the only trial evaluating this comparison (Lima 2004). Allocation concealment was inadequate and method of allocation was not satisfactory in this trial. In an available-case analysis, the mean difference for mean IOP at 12 months follow up was $1.14 \mathrm{~mm} \mathrm{Hg}$ (favoring ECP) and confidence intervals were wide and included the null value (95\% CI -1.93 to 4.21). At 24 months follow up mean difference was $0.66 \mathrm{~mm} \mathrm{Hg}$ favoring ECP (95\% CI -2.98 to 4.30).

Visual acuity (mean logMAR scores) (Analysis 2.2): Data on visual acuity outcomes were available only as mean $\log$ MAR scores at 24 months follow up. The mean difference for visual acuity measured as $\log$ MAR scores was 0.24 (95\% CI -0.04 to 0.52 ). Data on visual acuity at 12 months were not available. While the authors describe the proportion of participants with "worsening" and "stable" visual acuity, we were unable to find the definitions used for this study.

Anti-glaucoma medications at 24 months follow up (Analysis 2.3): Mean anti-glaucoma medications at 24 months follow up was greater in the Ahmed implant group but not statistically significant across groups. The mean difference was 0.50 (95\% CI -0.17 to 1.17 ).

\section{Ahmed implant with MMC versus Ahmed implant with balanced salt solution (BSS)}

Mean IOP at 12 months follow up (Analysis 3.1): One trial evaluated adjunct use of MMC with Ahmed implants (Costa 2004). The mean difference for mean IOP was -0.20 mm Hg (favoring Ahmed implant with MMC) and 95\% CI -2.82 to 2.42.

Anti-glaucoma medications at 12 months follow up (Analysis 3.2): The point estimate for the mean difference for mean anti-glaucoma medication use postoperatively was $0 \mathrm{~mm} \mathrm{Hg}$ and the $95 \%$ confidence interval was very wide and included the null value (95\% CI - 0.63 to $0.63)$.

\section{High-pressure Ahmed implant with adjunct MMC and partial Tenon's capsule resection (PTCR) versus Standard Ahmed implant with adjunct MMC alone}

Mean IOP at 12 months follow up (Analysis 4.1): One trial comparing mean IOP values with high-pressure Ahmed implant with PTCR and adjunct MMC with standard Ahmed implant with adjunct MMC alone (Susanna 2003) provided data on only 55\% and 70\% of participants in the two groups respectively. In an available-case analysis, the mean difference in IOP at 12 months follow up was $-1.13 \mathrm{~mm} \mathrm{Hg}$ (in favor of PTCR) but the $95 \%$ confidence interval included the null value (95\% CI -4.69 to 2.43 ).

\section{Double-plate Molteno implant versus Schocket (ACTSEB) shunt}

Mean IOP at six months follow up (Analysis 5.1): Two studies compared double-plate Molteno implant with the Schocket shunt (Smith 1992; Wilson 1992). Using data extracted from the published papers, with a fixed-effect model, we found a statistically significant chisquare test $(\mathrm{P}=0.03)$ and I-square value $79.6 \%$. Hence we do not report a pooled estimate 
for the mean difference. The mean difference for IOP at six months was $1.67 \mathrm{~mm} \mathrm{Hg}(95 \%$ CI -1.37 to 4.71) in favor of Schocket (ACTSEB) shunt in Smith 1992 and $2.50 \mathrm{~mm} \mathrm{Hg}$ (95\% CI -4.60 to -0.40) in favor of Molteno implant in Wilson 1992.

\section{Single-plate Molteno implant with oral corticosteroids versus single-plate Molteno implant alone}

Mean IOP at six months follow up (Analysis 6.1): One trial evaluated the effects of adjunct systemic corticosteroids with single-plate Molteno implant (Valimaki 1999). Mean IOP at 24 weeks (6 months) follow up was not statistically significantly different between the two groups. The point estimate for the mean difference for the mean IOP was $0 \mathrm{~mm} \mathrm{Hg}$ and the $95 \%$ confidence interval was very wide and included the null value (95\% C -4.75 to 4.75).

Visual acuity at six months follow up (Analysis 6.2): Relative risk for stable visual acuity, defined in our protocol as visual acuity within one line from baseline, was 1.22 (95\% CI 0.93 to 1.61 ) in favor of adjunct systemic corticosteroids. However, there were no events in the oral corticosteroid group for the visual acuity outcome, loss of vision. We defined loss of vision as loss of 2 or more lines from baseline, in our protocol.

Anti-glaucoma medications at 6 months follow up (Analysis 6.3): Participants on adjunct oral corticosteroids seemed to require more number of adjunct medications to control IOP postoperatively. The mean difference was 0.80 ( $95 \%$ CI 0.00 to 1.60 ).

\section{Pressure ridge, double-plate Molteno implant with MMC versus Molteno implant with balanced salt solution (BSS)}

Mean IOP (Analysis 7.1): In an available-case analysis, the mean difference for mean IOP at 12 months follow up was $0.30 \mathrm{~mm} \mathrm{Hg}$ (favoring Molteno implant with BSS) and the confidence interval was wide and included the null value (95\% CI -7.75 to 8.35 ).

Visual acuity (mean logMAR scores) (Analysis 7.2): The mean difference for visual acuity measured as $\log$ MAR scores at 12 months follow up was -0.60 (favoring Molteno implant with MMC) and the $95 \%$ CI -1.85 to 0.65 .

Anti-glaucoma medications at 12 months follow up (Analysis 7.3): There was no statistically significant difference in the mean postoperative anti-glaucoma medications used between the two groups at 12 months follow up. The mean difference was -0.30 (in favor of Molteno implant with MMC) and the 95\% CI - 1.04 to 0.44 .

\section{Single-plate Molteno implant versus double-plate Molteno implant}

IOP outcomes at final follow up (Analysis 8.1): One trial (Heuer 1992) compared IOP control in terms of success rates with definitions similar to what we stated in the 'Criteria for considering studies for this review' section above. We used the following definitions:

- $\quad$ success - a decrease of IOP by $15 \%$ from baseline at 12 months;

- complete success - IOP $\leq 21 \mathrm{~mm} \mathrm{Hg}$ on no adjunctive medications at 12 months; 
- qualified success - IOP $\leq 21 \mathrm{~mm} \mathrm{Hg}$ on medications at 12 months.

Heuer 1992 reported data only at final follow up. Mean (SD) follow up was 14.9 (6.8) months in the single-plate Molteno implant group and 16.4 (6.8) months in the double-plate Molteno implant group. The risk ratio of success as defined above for the double-plate Molteno implant group was 1.41 (95\% CI 0.98 to 2.01). Similarly, risk ratio of complete success for the double-plate Molteno implant was 1.18 (95\% CI 0.38 to 3.60); for qualified success, risk ratio was 2.18 (95\% CI 1.10 to 4.30$)$.

\section{$350 \mathrm{~mm}^{2}$ Baerveldt implant versus $500 \mathrm{~mm}^{2}$ Baerveldt implant}

Mean IOP (Analysis 9.1): One trial compared $350 \mathrm{~mm}^{2}$ Baerveldt implant versus $500 \mathrm{~mm}^{2}$ Baerveldt implant (Britt 1999). The mean difference in IOP at 12 months follow up was 0.50 $\mathrm{mm} \mathrm{Hg}$ (in favor of $350 \mathrm{~mm}^{2}$ Baerveldt implant) and $95 \% \mathrm{CI}-3.15$ to $4.15 \mathrm{~mm} \mathrm{Hg}$. The mean difference in IOP at longer terms of follow up in $\mathrm{mm} \mathrm{Hg}$ was -0.90 (95\% CI -3.12 to 1.32 ) at two years, -1.50 (95\% CI -3.55 to 0.55$)$ at three years, -1.40 (95\% CI - 4.55 to 1.75 ) at four years and -0.60 (95\% CI -3.93 to 2.73$)$ at five years follow up.

Lack of adequate data on outcomes precluded us from conducting analyses for several trials (Duan 2003; Gerber 1997; Hwang 2004; Kee 2001). Data available for Duan 2003 suffered from several losses to follow up. Hwang 2004 randomized both eyes in about 18\% of all participants in the trial. Participants in Gerber 1997 were followed up only for 12 weeks. While the authors of this study reported mean IOP values at 12 weeks, we were unable to find information on standard deviations for the mean IOP values in the two groups.

Similarly, no data on standard deviations were available in Kee 2001, which also adopted a different definition to dichotomize IOP outcomes as success and failure. Gerber 1997, Hwang 2004 and Kee 2001 did not find evidence of benefit of one treatment over the other, for treatments they evaluated, while Duan 2003 concluded adjunct MMC with the Hunan aqueous device was associated with better success rates in terms of IOP control compared with the Hunan aqueous device without MMC even with long-term follow up.

Complications-Though we intended to compare complication rates in different trials according to time of occurrence, we were unable to extract adequate information from the published papers. Our efforts to procure additional information from trial investigators were not fruitful due to unavailability of original data. No meta-Analysis was possible. However, details of important complications reported in the included trials are summarized in Table 2.

\section{Discussion}

\section{Summary of main results}

A meta-analysis of two trials found that trabeculectomy resulted in a lower mean IOP at 11 to 13 months follow up compared with Ahmed implant (Wilson 2000; Wilson 2003).

Although the I-square statistic of 53.5\% suggested the presence of statistical heterogeneity, the two trials were conducted with similar methodology, and the baseline IOP values were similar in both the trials. Further the effect estimates are in the same direction and the $95 \%$ confidence intervals for the effect estimate in both trials overlapped each other. However, we conducted anavailable-case analysis using standard deviations extracted from figures in 
the published paper as we were unable to procure data on the same. Additionally, inadequate methodological details warrant consideration such as the method of allocation concealment. One of these studies included previously unoperated eyes. The vast majority of previously published case series have described the utilization of shunts in eyes after previous failed standard filtering surgery.

Two studies compared double-plate Molteno implant with the Schocket shunt (Smith 1992; Wilson 1992). The results could not be pooled due to significant heterogeneity as noted above. One trial (Wilson 1992) found IOP was lower in the Molteno implant group. However, the results in this trial, though statistically significant, must be viewed in light of the methodological inadequacies including allocation concealment and exclusion of participants from the analyses. The second trial (Smith 1992) reported a greater decrease in IOP with the Schocket shunt. However, the 95\% confidence interval for the mean difference included the null value and hence was consistent with IOP being lower in either the Molteno implant group or the Schocket shunt group. The duration of follow up differed between the two trials, which could have been one of the sources of heterogeneity observed.

Of the three trials investigating the effectiveness of adjunctive MMC two found no evidence of its benefits in terms of mean postoperative IOP, $\log$ MAR visual acuity scores or postoperative anti-glaucoma medications at 12 months followup (Cantor 1998; Costa 2004). Duan 2003 concluded adjunct MMC with the Hunan aqueous device is associated with better success rates. However, these conclusions were influenced by losses to follow up in both treatment groups and while two trials (Cantor 1998; Costa 2004) reported an availablecase analysis, details in Duan 2003 are not clear.

Results from one trial (Valimaki 1999) suggest no evidence of benefit with the use of systemic steroids as a method of decreasing bleb fibrosis. However, these conclusions are limited by methodological inadequacies and the small sample size in the trial. No evidence of benefit with excision of Tenon's capsule was found in one quasi-randomized trial (Susanna 2003). One quasi-randomized trial demonstrated no evidence of superiority of Ahmed implant or endocyclophotocoagulation over each other in terms of mean IOP at 12 months follow up, mean logMAR visual acuity, and complications at 24 months follow up (Lima 2004). Where success in controlling IOP was analyzed using Kaplan-Meier or lifetable analyses, varied definitions of "success" and lack of adequate information precluded us from conducting analyses based on Kaplan-Meier curves.

Analysis of mean difference in IOP at different times of follow up showed no evidence of benefit of using a Baerveldt implant with a greater surface area. Though the point estimate tended towards the $500 \mathrm{~mm}^{2}$ Baerveldt implant, the $95 \%$ confidence intervals included the null value. However, life-table analyses reported in the published trial report showed statistically significant differences in cumulative success rates in favor of the $350 \mathrm{~mm}^{2}$ Baerveldt implant (Britt 1999). Success in this study was defined as an IOP $\geq 6 \mathrm{~mm} \mathrm{Hg}$ and $\leq 21 \mathrm{~mm} \mathrm{Hg}$.

In a comparison of single-plate Molteno implant with double-plate Molteno implant, an available case analysis of IOP as a dichotomous outcome, defined as stated earlier in this 
review, showed statistically significant differences favoring the double-plate Molteno implant in only two of the three defined categories, "success" (IOP < 21 or at least a $30 \%$ reduction from baseline) and "qualified success" (IOP $<21$ on medications). Though the relative risks of success and qualified success suggested statistical significance, the confidence interval was close to the null value for the outcome, "success" (0.98 to 2.01), and was quite wide for the outcome, "qualified success" (1.10 to 4.30). However, the authors of this trial (Heuer 1992) report a statistically significant difference in success rates using a life-table analysis ( $\mathrm{p}$-value for log-rank test $=0.0035$ ). For this analysis, they defined 'success' to mean a final IOP at least $6 \mathrm{~mm} \mathrm{Hg}$ but not greater than $21 \mathrm{~mm} \mathrm{Hg}$ without additional glaucoma surgery or devastating complications.

Complications were too variably reported in this series of trials to allow comparative tabulation of intraoperative, early or late complications associated with specific aqueous shunts. Reported adverse effects of interest included corneal injury (endothelial decompensation/edema); suprachoroidal hemorrhage; retinal detachment; cataract; hypotony;infection; strabismus; host-immune response to anterior chamber tubes (keratic precipitates); post-operative hypertensive phase duration; and clinical failure. Late hypotony and late wound leaks were also variably reported and could not be fairly compared across trials employing different or the same devices.

\section{Quality of the evidence}

Overall, the trials included in this review were of poor methodological quality. The method of randomization was clearly adequate in only five trials and allocation concealment was clearly adequate in only two trials. Only three trials reported an intention-to-treat analysis. The results of the meta-analysis reported in this review are influenced by methodological limitations as well as the extraction of data on mean IOP from the published figures, although two authors independently extracted the data from the figures in published papers.

\section{Authors' Conclusions}

\section{Implications for practice}

Meta-analysis of two trials comparing Ahmed implant versus trabeculectomy reinforces the commonly held impression among glaucoma surgeons that trabeculectomy, especially with anti-fibrotic enhancement intraoperatively, will likely produce lower IOP than aqueous shunts. However the differences in IOP outcomes between Ahmed shunts and trabeculectomy were surprisingly small, only $3.81 \mathrm{~mm} \mathrm{Hg}$ (95\% CI 1.94 to $5.69 \mathrm{~mm} \mathrm{Hg}$ ). Based on this review, no specific aqueous shunt stands out as clearly clinically superior with regard to either safety or efficacy. Practitioners should base their choice of device on their own experience and continue to utilize the shunt with which they are most comfortable.

Although frequencies of complications among control and experimental groups in a study of Ahmed implants with and without MMC seemed similar, further studies are needed to better evaluate short or long-term risks. However, two trials did not show an IOP outcome advantage with MMC use intraoperatively. There is little or no incentive, based on this review, to recommend adjunctive MMC use with aqueous shunts. 


\section{Implications for research}

Additional trials should be organized to compare devices with regard to specific issues of safety including the risks of immediate postoperative hypotony and its complications such as choroidal effusion and suprachoroidal hemorrhage in various glaucoma disease groups. Future clinical trials should use standard definitions and terminology for glaucoma types and complications. While IOP is measured as a continuous outcome, it can also be categorized and analyzed as a dichotomous outcome. Categorization of the outcome helps conduct an intention to treat analysis by adopting methods such as Kaplan-Meier analyses. It is very apparent that standardization of definitions for outcomes such as "success", "failure", "qualified success", etc., to allow for comparison between trials, would greatly enhance research synthesis. Data collection and data collection intervals should also be standardized and follow up should be continued for several years. The postoperative hypertensive phase and inflammatory reaction should be better defined and characterized to allow more rational use of anti-glaucoma and anti-inflammatory agents pre and postoperatively.

Neovascular glaucoma in particular is a frequently encountered complex glaucoma in which the use of aqueous shunts has been growing. Planning for future studies of aqueous shunts in neovascular or other complicated glaucomas should include pre-study planning, ideally for multi-center trials, to allow sufficient sample sizes to be recruited in each disease type to answer specific study questions such as:

- Are shunts as effective as trabeculectomy?

- Is one aqueous shunt superior to any other?

- When is the optimal time to employ aqueous shunts in neovascular or other complicated glaucomas?

- Are there any differences in effectivness or complications rates with anterior chamber compared with pars-plana insertion of shunt tubes?

- Is there an optimum explant size, shape, or material?

- Do intraoperative or postoperative complications differ among available shunts?

- Do all types of aqueous shunts have a hypertensive phase and, if so, what is the most rational management or method of prevention?

- What are the optimal pre and postoperative treatment regimens for use with aqueous shunts for various glaucoma types?

- Which supplemental anti-glaucoma medications are best with aqueous shunts?

- What is the role, if any, for antifibrotic agents as adjuncts to utilizing various aqueous shunts?

- How can surgical techniques be changed to minimize erosions of tubes or explants?

- Are all cyclodestructive interventions just as efficacious and equally complicated as aqueous shunts? 


\section{Acknowledgments}

The Cochrane Eyes and Vision Group US Project was earlier based at Brown University, USA, which provided infrastructural support in developing this review. The US Cochrane Center provided office space and editorial support for the development of the protocol for this review. We thank Catey Bunce, Suzanne Brodney-Folse and Keith Barton for peer review comments on the protocol for this review. We thank Richard Wormald, Roberta Scherer, Barbara Hawkins, Catey Bunce, Katherine Henshaw, Keith Barton and Augusto Azuaro-Blanco for their helpful comments on earlier versions of this review. Karen Blackhall at the Cochrane Eyes and Vision Group devised and conducted the electronic searches for this review.

\section{Sources of Support}

Internal sources

- Department of Ophthalmology, University of Southern California, USA.

- Johns Hopkins University, USA.

External sources

- Contract N-01-EY2-1003, National Eye Institute, National Institutes of Health, USA.

- $\quad$ Allergan, Inc (unrestricted educational grant), USA.

\section{Characteristics Of Studies}

\section{Characteristics of included studies [ordered by study ID]}

Britt 1999

\begin{tabular}{|c|c|}
\hline Methods & $\begin{array}{l}\text { Method of randomization: random numbers table used to generate the allocation sequence. } \\
\text { Number randomized: } 107 \text { ( } 55 \text { to } 350 \mathrm{~mm} 2 \text { Baerveldt implant arm; } 52 \text { to } 500 \mathrm{~mm} 2 \\
\text { Baerveldt implant arm). } \\
\text { Exclusions after randomization (total and per group): none. } \\
\text { Losses to follow up: } 2 \text { participants in each arm were lost to follow up either because of } \\
\text { operative complications or for unknown reasons. } \\
\text { Method of allocation concealment: "Operating room personnel read the assignment from } \\
\text { the randomization list, to which the surgeons were masked." } \\
\text { Outcome assessor masking: not reported. } \\
\text { Intention-to-treat analysis: no. Analysis excludes } 2 \text { participants in each arm who were lost } \\
\text { to follow up. Unusual study design: none. }\end{array}$ \\
\hline Participants & $\begin{array}{l}\text { Age: mean (SD) } 67.5 \text { (18) years in } 350 \mathrm{~mm} 2 \text { Baerveldt implant arm; } 68.9 \text { (16.7) years in } \\
500 \text { mm2 } \\
\text { Baerveldt implant arm. } \\
\text { Sex: not reported. } \\
\text { Inclusion Criteria: medically uncontrollable glaucoma associated with aphakia, } \\
\text { pseudophakia or failed filtering procedures. } \\
\text { Exclusion Criteria: age less than } 12 \text { years; neovascular glaucoma; uveitis; previous muscle } \\
\text { surgery; extensive scarring; existing scleral buckles or glaucoma implants; prior } \\
\text { cyclodestructive procedures. } \\
\text { Equivalence of baseline characteristics: age; race; types of glaucoma; mean IOP were } \\
\text { similar in both treatment arms at baseline. } \\
\text { Diagnoses in participants: aphakic; pseudophakic; failed filtering procedures. }\end{array}$ \\
\hline Interventions & $\begin{array}{l}\text { Treatment: } 500 \mathrm{~mm} 2 \text { Baerveldt implant. } \\
\text { Control: } 350 \mathrm{~mm} 2 \text { Baerveldt implant. } \\
\text { Not all implants were placed temporally in both arms. } \\
\text { All eyes received scleral patch grafts. } \\
\text { Topical atropine sulfate }(1 \%) \text { was instilled after completion of procedure. Subconjunctival } \\
\text { injections of } 12 \mathrm{mg} \text { dexamethasone phosphate and } 20 \mathrm{mg} \text { gentamicin sulfate were } \\
\text { administered separately after all procedures followed by overnight patching. } \\
\text { Postoperative regimen included topical tobramycin for } 2 \text { weeks, } 1 \% \text { atropine sulfate and } \\
1 \% \text { prednisolone acetate or phosphate for } 4 \text { to } 6 \text { weeks. }\end{array}$ \\
\hline Outcomes & $\begin{array}{l}\text { Primary outcome: IOP control. } \\
\text { Complete success: IOP between } 6 \mathrm{~mm} \mathrm{Hg} \text { and } 21 \mathrm{~mm} \mathrm{Hg} \text { inclusive without additional } \\
\text { glaucoma surgery and without devastating complications. } \\
\text { Qualified success: IOP between } 6 \mathrm{~mm} \mathrm{Hg} \text { and } 21 \mathrm{~mm} \mathrm{Hg} \text { inclusive with additional } \\
\text { glaucoma surgery and without devastating complications. } \\
\text { Qualified failure: IOP }>21 \mathrm{~mm} \mathrm{Hg} \text { with medications }\end{array}$ \\
\hline
\end{tabular}




\begin{tabular}{l|l|l} 
& $\begin{array}{l}\text { Complete failure: additional glaucoma surgery; hypotony (IOP < 6 mm Hg); devastating } \\
\text { complications; loss of light perception. } \\
\text { Secondary outcomes: visual acuity; number of anti-glaucoma medications; complications }\end{array}$ \\
\hline Notes & $\begin{array}{l}\text { Country and period of study: USA. Enrollment period was from March 21, 1991 to April } \\
29,1993 .\end{array}$ \\
& $\begin{array}{l}\text { Follow-up intervals: not reported. Outcomes were analyzed at 1, 2, 3, 4 and 5 years } \\
\text { postoperatively. "Data for the current report were collected during the interval between the } \\
\text { installation of the implants and the most recent ophthalmic visits on or before September 1, } \\
1997 . . . "\end{array}$ \\
\hline Risk of bias & \multicolumn{2}{|l}{} \\
\hline Item & Authors' judgement & Description \\
\hline Allocation concealment? & Yes & A-Adequate \\
\hline
\end{tabular}

\section{Cantor 1998}

\begin{tabular}{|c|c|}
\hline Methods & $\begin{array}{l}\text { Method of randomization: unclear. "participants were randomized to receive either MMC } \\
\text { or a control solution (balanced salt solution, BSS) prospectively." } \\
\text { Number randomized: } 25 \text { ( } 12 \text { to Molteno implant with MMC arm and } 13 \text { to Molteno implant } \\
\text { with BSS arm). } \\
\text { Exclusions after randomization (total and per group): None } \\
\text { Losses to follow up: } 2 \text { participants in Molteno implant with MMC arm and } 1 \text { patient in } \\
\text { Molteno implant without MMC arm at } 12 \text { months of follow up. Reasons not reported. } \\
\text { Method of allocation concealment: not reported. } \\
\text { Participant masking: not reported. } \\
\text { Provider masking: "The surgeon remained masked to which solution was being used." } \\
\text { Balanced salt solution was stained with gentian violet. } \\
\text { Outcome assessor masking: Not reported. } \\
\text { Intention-to-treat analysis: no. Participants lost to follow up at } 12 \text { months were excluded } \\
\text { from the analysis. } \\
\text { Unusual study design: none. }\end{array}$ \\
\hline Participants & $\begin{array}{l}\text { Age: mean (SD) } 66.4 \text { (14) years in Molteno implant with MMC arm; } 67.1 \text { (11.4) years in } \\
\text { control arm. } \\
\text { Sex: } 50 \% \text { in Molteno implant with MMC arm and 54\% in control arm were females. } \\
\text { Inclusion criteria: Age } 21 \text { years or older; any race; either sex; any lens status; primary } \\
\text { open-angle glaucoma; pigment dispersion glaucoma; pseudoexfoliation glaucoma; primary } \\
\text { angle-closure glaucoma; neovascular glaucoma; traumatic glaucoma; any secondary open } \\
\text { or angle-closure glaucoma; congenital glaucoma; inflammatory glaucoma; any previous } \\
\text { ocular surgery other than scleral buckling. } \\
\text { Exclusion criteria: previous aqueous implant shunt placement; previous scleral encircling } \\
\text { band placement; pregnancy or lactation. } \\
\text { Equivalence of baseline characteristics: mean IOP at baseline was } 41.54 \text { (17.8) mm Hg in } \\
\text { Molteno implant with MMC arm and } 34.65 \text { (8.43) mm Hg in control arm at baseline. } 3 \\
\text { black participants in control arm, none in Molteno implant with MMC arm. } \\
\text { Diagnoses in participants: neovascular glaucoma; chronic angle-closure glaucoma; aphakia; } \\
\text { primary open- } \\
\text { angle glaucoma; glaucoma secondary to trauma; ruptured globe; inflammation. }\end{array}$ \\
\hline Interventions & $\begin{array}{l}\text { Treatment: pressure-ridge, double-plate Molteno implant with topical MMC }(0.4 \mathrm{mg} / \mathrm{ml} \\
\text { applied for } 2 \text { minutes with a sponge soaked in the solution). } \\
\text { Control: pressure-ridge, double-plate Molteno implant with BSS stained with gentian } \\
\text { violet. } \\
\text { All patients in both arms received scleral patch grafts. } \\
\text { Postoperative management included } 1 \% \text { prednisolone acetate and gentamicin four times a } \\
\text { day, } 1 \% \text { atropine } 2 \text { to } 4 \text { times a day and glaucoma medications (except for carbonic } \\
\text { anhydrase inhibitors)in the fellow eye as required }\end{array}$ \\
\hline Outcomes & $\begin{array}{l}\text { IOP control reported as final mean IOP; visual acuity; number of postoperative } \\
\text { medications; complications. }\end{array}$ \\
\hline Notes & $\begin{array}{l}\text { Country and period of study: USA. Study period not reported. } \\
\text { Follow-up intervals: Postoperative week } 1 \text {, months } 1,3,6 \text { and } 12 \text {. }\end{array}$ \\
\hline \multicolumn{2}{|l|}{ Risk of bias } \\
\hline Item & Authors' judgement \\
\hline Allocation concealment? & B - Unclear \\
\hline
\end{tabular}

Cochrane Database Syst Rev. Author manuscript; available in PMC 2015 January 13. 


\section{Costa 2004}

\begin{tabular}{|c|c|c|}
\hline Methods & \multicolumn{2}{|c|}{$\begin{array}{l}\text { Method of randomization: not reported - "participants were randomized to receive } \\
\text { intraoperative MMC or a placebo." } \\
\text { Number randomized: } 60 \text { ( } 34 \text { to Ahmed valve with MMC and } 26 \text { to Ahmed valve implant } \\
\text { with placebo). } \\
\text { Exclusions after randomization (total and per group): None. } \\
\text { Losses to follow up: no losses of follow up reported explicitly. } \\
\text { Method of allocation concealment: not reported. } \\
\text { Participant masking: not reported. } \\
\text { Provider masking: not reported. } \\
\text { Outcome assessor masking: not reported. } \\
\text { Intention-to-treat: unclear } \\
\text { Unusual study design: none. }\end{array}$} \\
\hline Participants & \multicolumn{2}{|c|}{$\begin{array}{l}\text { Age: mean (SD) } 62.7 \text { (16.5) years in Ahmed implant with MMC arm; } 61.1 \text { (20.6) years in } \\
\text { Ahmed implant with placebo arm. } \\
\text { Sex: } 32 \% \text { in Ahmed implant with MMC arm and 50\% in Ahmed implant with placebo arm } \\
\text { were females. } \\
\text { Inclusion criteria: uncontrolled glaucoma requiring glaucoma drainage device implantation. } \\
\text { Exclusion criteria: younger than } 18 \text { years of age; learning difficulties; mental illness; } \\
\text { dementia; unconsciousness or severe illness. } \\
\text { Equivalence of baseline characteristics: Age; race; lens status; prior glaucoma surgery } \\
\text { status; IOP similar in the two arms at baseline. } \\
\text { Diagnoses in participants: primary open-angle glaucoma; chronic angle-closure glaucoma; } \\
\text { neovascular glaucoma; aphakic/pseudophakic, congenital, traumatic glaucomas; } \\
\text { inflammatory and steroid-induced glaucoma; glaucoma following penetrating keratoplasty. }\end{array}$} \\
\hline Interventions & \multicolumn{2}{|c|}{$\begin{array}{l}\text { Treatment: Ahmed valve implant with } 0.5 \mathrm{mg} / \mathrm{ml} \text { solution of MMC placed on the episclera, } \\
\text { under the conjunctiva and Tenon's capsule at the site for implant plate for } 5 \text { minutes. } \\
\text { Control: Ahmed valve implant with topical application of BSS using a soaked sponge on } \\
\text { the episclera at site for implant plate for } 5 \text { minutes. } \\
\text { Postoperative regimen included a topical antibiotic and a cycloplegic for } 2 \text { to } 4 \text { weeks and } \\
\text { topical steroids for approximately } 2 \text { months. }\end{array}$} \\
\hline Outcomes & \multicolumn{2}{|c|}{$\begin{array}{l}\text { IOP control reported as final mean IOP and surgical success; best-corrected visual acuity; } \\
\text { number of anti-glaucoma medications; complications. } \\
\text { Surgical success: (1) postoperative IOP between } 6 \text { and } 21 \mathrm{~mm} \mathrm{Hg} \text { with or without anti- } \\
\text { glaucoma medications or (2) IOP reduction of at least } 30 \% \text { relative to preoperative values. }\end{array}$} \\
\hline Notes & \multicolumn{2}{|c|}{$\begin{array}{l}\text { Country and period of study: Brazil, Scotland, USA, Canada. Study period was not } \\
\text { reported. } \\
\text { Follow-up intervals: postoperative day 1, weeks } 1 \text { and } 2 \text {, months } 1,3,6,12 \text { and } 18 .\end{array}$} \\
\hline \multicolumn{3}{|l|}{ Risk of bias } \\
\hline Item & Authors' judgement & Description \\
\hline Allocation concealment? & Unclear & B - Unclear \\
\hline
\end{tabular}

Duan 2003

Methods
Method of randomization: not reported "randomization was used".

Number randomized: 159 ( 4 eyes to HAD without MMC and 65 eyes to HAD with MMC).

Exclusions after randomization (total and per group): none reported.

Losses to follow up: 23 (5 not accounted for) in HAD without MMC and 20 (5 eyes more

than the randomized number included) in HAD with MMC arms at 1 year.

32 (13 not accounted for) in HAD without MMC and 27 (6 not accounted for) in HAD with

MMC arms at 24 months of follow up.

43 (15 not accounted for) in HAD without MMC and 37 (9 not accounted for) in HAD with

MMC arms at 36 months of follow up.

64 in HAD without MMC and 51 (1 eye more than the number enrolled was included) in

HAD with MMC arms at 48 months of follow up.

70 ( 2 not accounted for) in HAD without MMC and 56 in HAD with MMC arms at 60

months of follow up.

72 (8 not accounted for) in HAD without MMC and all participants in HAD with MMC

arms at 72 months of follow up.

Reasons were not reported.

Method of allocation concealment: not reported.

Outcome assessor masking: not reported. 
Intention-to-treat analysis: no. Participants lost to follow-up were excluded from the analysis.

Unusual study design: 5 participants served as their own controls.

\begin{tabular}{|c|c|c|}
\hline Participants & \multicolumn{2}{|c|}{$\begin{array}{l}\text { Age: average age reported as } 49.71 \pm 6.9 \text { years. Group-wise age distributions not reported. } \\
\text { Sex: } 85 \text { male patients ( } 87 \text { eyes) and } 69 \text { female patients ( } 72 \text { eyes). Group-wise gender } \\
\text { distribution not reported. } \\
\text { Inclusion criteria: refractory glaucoma (IOP }>25 \mathrm{~mm} \mathrm{Hg} \text { on combined pharmacologic } \\
\text { therapy). } \\
\text { Exclusion criteria: none reported. } \\
\text { Equivalence of baseline characteristics: mean IOP at baseline is similar in both intervention } \\
\text { groups. } \\
\text { However, no information on other baseline characters was reported. HAD without MMC } \\
\text { arm had almost twice as many patients with aphakia as in HAD with MMC arm. } \\
\text { Diagnoses in participants: aphakia; pseudophakia; neovascular glaucoma; uveitic } \\
\text { glaucoma; traumatic glaucoma; primary angle-closure glaucoma; juvenile glaucoma; ICE }\end{array}$} \\
\hline Interventions & \multicolumn{2}{|c|}{$\begin{array}{l}\text { Treatment: HAD with adjunctive topical application of } 0.4 \mathrm{mg} / \mathrm{ml} \text { MMC with a sponge, } \\
\text { applied to the sclera near the equator for } 1 \text { to } 5 \text { minutes followed by rinsing of extra MMC } \\
\text { with balanced salt solution. (Duration of MMC was determined as follows: minimum } \\
\text { duration was } 1 \text { minute with addition of } 1 \text { minute with each of the following characteristics: } \\
\text { age of patient less than } 40 \text { years; thick connective tissue; rubeosis iris; IOP }>40 \mathrm{~mm} \mathrm{Hg} \\
\text { after combined drug therapy). } \\
\text { Control: HAD without MMC. }\end{array}$} \\
\hline Outcomes & \multicolumn{2}{|c|}{$\begin{array}{l}\text { Visual acuity (including best corrected visual acuity) measured with "international } \\
\text { standardized chart"; IOP control with measurements using Goldmann applanation (success: } \\
6 \mathrm{~mm} \mathrm{Hg}<\mathrm{IOP}>21 \mathrm{~mm} \mathrm{Hg} \text { ); visual field of those patients with good visual acuity; } \\
\text { standardized ocular echography; slit lamp biomicroscope examination. }\end{array}$} \\
\hline Notes & \multicolumn{2}{|c|}{$\begin{array}{l}\text { Country and period of study: China, July } 1995 \text { to July } 2001 \\
\text { Follow-up intervals: Every } 3 \text { months for the first postoperative year and every } 6 \text { months } \\
\text { thereafter. }\end{array}$} \\
\hline \multicolumn{3}{|l|}{ Risk of bias } \\
\hline Item & Authors' judgement & Description \\
\hline Allocation concealment? & Unclear & B - Unclear \\
\hline
\end{tabular}

\section{Gerber 1997}

\begin{tabular}{|c|c|}
\hline Methods & $\begin{array}{l}\text { Method of randomization: not clear. "Randomization procedure consisted of a nurse } \\
\text { selecting a card from a stack at the time of the patient's entry into the operating room." } \\
\text { Number randomized: } 30 \text { ( } 15 \text { in each arm). } \\
\text { Exclusions after randomization (total and per group): none. } \\
\text { Losses to follow up: } 1 \text { patient in the Pressure ridge Molteno implant arm had penetrating } \\
\text { keratoplasty at } 8 \text { weeks and did not have } 12 \text { week follow-up data. } \\
\text { Method of allocation concealment: not reported. } \\
\text { Outcome assessor masking: not reported. } \\
\text { Intention-to-treat analysis: no. Patients were excluded from analysis from the point they } \\
\text { underwent additional surgical procedures in the postoperative period. } \\
\text { Unusual study design: } 1 \text { patient had both eyes randomized. }\end{array}$ \\
\hline Participants & $\begin{array}{l}\text { Age: mean age } 61.5 \text { years in Pressure ridge Molteno implant arm; } 64.5 \text { years in Standard } \\
\text { Molteno implant with suture ligation arm. Standard deviations were not reported. } \\
\text { Sex: } 67 \% \text { in Pressure ridge Molteno implant arm and } 60 \% \text { in Standard Molteno implant } \\
\text { arm were females. } \\
\text { Inclusion criteria: inclusion criteria were not stated explicitly. } \\
\text { Exclusion criteria: patients with prior cyclodestructive procedures were excluded. } \\
\text { Equivalence of baseline characteristics: age; race; gender and type of glaucoma were } \\
\text { similar in the two arms at baseline. } \\
\text { Diagnoses in participants: pseudophakic/aphakic glaucoma; primary open-angle glaucoma; } \\
\text { neovascular glaucoma; inflammatory glaucoma; chronic angle-closure glaucoma; post- } \\
\text { penetrating keratoplasty; ectopia lentis; ICE syndrome. }\end{array}$ \\
\hline Interventions & $\begin{array}{l}\text { Treatment: Pressure-ridge, double-plate Molteno implant without tube ligature. } \\
\text { Control: standard double-plate Molteno implant with 9-0 nylon suture ligation. } \\
\text { A donor scleral graft was placed in all patients. Postoperative medications included a } \\
\text { combined steroid-antibiotic ointment for night-time use and a separate antibiotic and } \\
\text { steroid to be applied four times a day for at least } 1 \text { month following surgery. Steroids were } \\
\text { phased out after } 1 \text { month at the discretion of the surgeon. }\end{array}$ \\
\hline
\end{tabular}




\begin{tabular}{l|l|l} 
Outcomes & IOP control reported as final mean IOP; anterior chamber depth; visual acuity. \\
\hline Notes & $\begin{array}{l}\text { Country and period of study: USA. Study period not reported. } \\
\text { Follow-up intervals: postoperative days 1 and 2, weeks 1, 2, 4, 8 and 12. }\end{array}$ \\
\hline Risk of bias & Authors' judgement & Description \\
\hline Item & B - Unclear \\
\hline Allocation concealment? & Unclear & R
\end{tabular}

Heuer 1992

\begin{tabular}{|c|c|}
\hline Methods & $\begin{array}{l}\text { Method of randomization: random number table was used to generate the allocation } \\
\text { sequence. Randomization was stratified for } 1 \text { stage and } 2 \text { stage installations. } \\
\text { Number randomized: } 132 \text { ( } 66 \text { to Double plate Molteno implant and } 66 \text { to Single plate } \\
\text { Molteno implant). } \\
\text { Exclusions after randomization (total and per group): } 31 \text { ( } 15 \text { patients in Double plate } \\
\text { Molteno implant arm and } 16 \text { in Single plate Molteno implant arm were excluded after the } \\
\text { first stage of installation "because either their IOPs were adequately controlled or their } \\
\text { visual potentials were subsequently judged to be inadequate to justify further intraocular } \\
\text { surgical procedures." } \\
\text { Losses to follow up: } 1 \text { patient in each arm with less than } 6 \text { months of follow up. } \\
\text { Method of allocation concealment: surgeons were masked to allocation lists (personal } \\
\text { communication). } \\
\text { The lists, which were kept in large envelopes in a drawer in one of the operating rooms, } \\
\text { were not accessible to the operating surgeons. Treatment assignment was declared by one } \\
\text { of the operating room personnel after the surgeon confirmed feasibility of the procedure. } \\
\text { Outcome assessor masking: not reported. } \\
\text { Intention-to-treat analysis: no. } 31 \text { patients excluded after randomization were not included } \\
\text { in the analysis. } \\
\text { Unusual study design: none. }\end{array}$ \\
\hline Participants & $\begin{array}{l}\text { Age: mean (SD) } 62.1 \text { (20.8) years in Double plate Molteno implant arm; } 61.1 \text { (16.2) years } \\
\text { in Single plate Molteno implant arm. } \\
\text { Sex: not reported. } \\
\text { Inclusion criteria: medically uncontrollable non-neovascular glaucoma in patients with } \\
\text { aphakia or pseudophakia. } \\
\text { Exclusion criteria: concurrent retinal detachment; first stage of Molteno implantation } \\
\text { performed during non-glaucoma surgery in eye with marginally functioning filtering bleb; } \\
\text { prior cyclodestructive procedures; prior Molteno implantation in eye undergoing surgery; } \\
\text { prior scleral buckling procedure; recent corneoscleral or corneal wound. } \\
\text { Equivalence of baseline characteristics: the two groups were similar with respect to age, } \\
\text { preoperative IOP, and type of glaucoma. } \\
\text { Diagnoses in participants: open-angle glaucoma; angle-closure glaucoma; uveitic } \\
\text { glaucoma; congenital glaucoma; traumatic glaucoma; glaucoma of uncertain etiology. }\end{array}$ \\
\hline Interventions & $\begin{array}{l}\text { Treatment: Double-plate Molteno implant. } \\
\text { Control: Single-plate Molteno implant. } \\
\text { Subconjunctival injections of } 12 \text { mg dexamethasone phosphate and } 20 \text { mg of gentamicin } \\
\text { sulfate were administered separately after most procedures. Postoperative regimen in both } \\
\text { arms included topical corticosteroids ( } 1 \% \text { prednisolone acetate or phosphate) for } 2 \text { to } 4 \\
\text { months, tapered based on the intraocular and bleb capsule inflammation, topical atropine } \\
\text { sulfate }(1 \%) \text { for } 4 \text { to } 6 \text { weeks and topical antibiotics }(0.3 \% \text { gentamicin or } 0.3 \% \\
\text { tobramycin)for } 1 \text { to } 4 \text { weeks. }\end{array}$ \\
\hline Outcomes & $\begin{array}{l}\text { Primary outcome: IOP control. } \\
\text { Success: IOP between } 6 \text { and } 21 \mathrm{~mm} \mathrm{Hg} \text { inclusive with no additional glaucoma surgery } \\
\text { (other than surgical tube ligature release) and no devastating complications. } \\
\text { Complete success: no additional glaucoma procedures, final IOP }>5 \mathrm{~mm} \mathrm{Hg} \text { and }<22 \mathrm{~mm} \\
\mathrm{Hg} \text { without anti-glaucoma medications. } \\
\text { Qualified success: no additional glaucoma procedures; final IOP }>5 \mathrm{~mm} \mathrm{Hg} \text { and }<22 \mathrm{~mm} \\
\mathrm{Hg} \text { with anti-glaucoma medications. } \\
\text { Qualified failure: no additional glaucoma procedures; final IOP }>21 \mathrm{~mm} \mathrm{Hg} \text {. } \\
\text { Complete failure: additional glaucoma procedures; loss of light perception attributed to } \\
\text { glaucoma; final IOP < } 6 \mathrm{~mm} \mathrm{Hg} \text {; or devastating complications. } \\
\text { Secondary outcomes: visual acuity; complications; number of postoperative anti-glaucoma } \\
\text { medications. }\end{array}$ \\
\hline Notes & $\begin{array}{l}\text { Country and period of study: USA. March } 1988 \text { to February } 1990 \\
\text { Follow-up intervals: intervals at which outcome was assessed was not explicitly reported. } \\
\text { However, success at months } 6,12,18 \text { and } 24 \text { were reported in the results. }\end{array}$ \\
\hline
\end{tabular}




\begin{tabular}{l|l|l}
\multicolumn{2}{l|}{ Risk of bias } \\
\hline Item & Authors' judgement & Description \\
\hline Allocation concealment? & Yes & A-Adequate \\
\hline
\end{tabular}

\section{Hwang 2004}

\begin{tabular}{|c|c|c|}
\hline Methods & \multicolumn{2}{|c|}{$\begin{array}{l}\text { Method of randomization: not clear. "Randomization procedure consisted of a nurse } \\
\text { selecting a card from a stack at the time of the patient's entry into the operating room." } \\
\text { Number randomized: } 30 \text { ( } 15 \text { in each arm). } \\
\text { Exclusions after randomization (total and per group): none. } \\
\text { Losses to follow up: } 1 \text { patient in the Pressure ridge Molteno implant arm had penetrating } \\
\text { keratoplasty at } 8 \text { weeks and did not have } 12 \text { week follow-up data. } \\
\text { Method of allocation concealment: not reported. } \\
\text { Outcome assessor masking: not reported. } \\
\text { Intention-to-treat analysis: no. Participants were excluded from analysis from the point they } \\
\text { underwent additional surgical procedures in the postoperative period. } \\
\text { Unusual study design: } 1 \text { patient had both eyes randomized. }\end{array}$} \\
\hline Participants & \multicolumn{2}{|c|}{$\begin{array}{l}\text { Age: mean (SD) } 44.3 \text { (25.3) years in Ahmed implant group; } 42.7 \text { (23) years for the Ahmed } \\
\text { implant with pericardial membrane surface expansion group. Participants ranged from } 9 \text { to } \\
73 \text { years and } 2 \text { to } 81 \text { years in the two groups, respectively. } \\
\text { Sex: proportion of females in each intervention group is unclear. } \\
\text { Inclusion criteria: glaucoma not responsive to medical, laser or previous surgical treatment. } \\
\text { Exclusion criteria: none reported. } \\
\text { Equivalence of baseline characteristics: mean IOP; age and diagnoses in participants at } \\
\text { baseline is similar in both intervention groups. } \\
\text { Diagnoses in participants: neovascular glaucoma; secondary glaucoma; pseudophakic } \\
\text { glaucoma; failed trabeculectomy. }\end{array}$} \\
\hline Interventions & \multicolumn{2}{|c|}{$\begin{array}{l}\text { Treatment: Ahmed valve implant with a pericardial membrane surface expansion. } \\
\text { Control: Ahmed valve implant. } \\
\text { Participants in both treatment groups received subconjunctival injections of } 0.3 \mathrm{ml} \\
\text { gentamicin }(40 \mathrm{mg} / \mathrm{ml}) \text { and dexamethasone }(5 \mathrm{mg} / \mathrm{ml}) \text { soon after surgery. Postoperative } \\
\text { treatment in both groups included topical corticosteroids and antibiotics. }\end{array}$} \\
\hline Outcomes & \multicolumn{2}{|c|}{$\begin{array}{l}\text { IOP control: } \\
\text { Success: IOP }<22 \mathrm{~mm} \mathrm{Hg} \text { and }>5 \mathrm{~mm} \mathrm{Hg} \text { without additional glaucoma surgery and } \\
\text { without loss of light perception. } \\
\text { Complete success: IOP control as defined above without use of anti-glaucoma medications. } \\
\text { Qualified success: IOP control as defined above with adjunctive anti-glaucoma medications } \\
\text { Failure: IOP }>21 \mathrm{~mm} \mathrm{Hg} \text { on maximally tolerated medications or }<6 \mathrm{~mm} \mathrm{Hg} \text {; or additional } \\
\text { glaucoma surgery including laser treatment; or loss of light perception; or phthisis bulbi. } \\
\text { Hypotony defined as IOP }<6 \mathrm{~mm} \mathrm{Hg} \text { in } 2 \text { consecutive visits. } \\
\text { Postoperative hypertensive phase defined as IOP }>21 \mathrm{~mm} \mathrm{Hg} \text { in the first } 6 \text { postoperative } \\
\text { months. }\end{array}$} \\
\hline Notes & \multicolumn{2}{|c|}{$\begin{array}{l}\text { Country and period of study: Korea; study period was not reported. } \\
\text { Follow-up intervals: not explicitly reported. } \\
\text { Mean (SD) of total follow up was } 14.9 \text { (4.3) months in Ahmed implant group and } 11.5(5.1) \\
\text { months in Ahmed implant with surface expansion group. }\end{array}$} \\
\hline \multicolumn{3}{|l|}{ Risk of bias } \\
\hline Item & Authors' judgement & Description \\
\hline Allocation concealment? & Unclear & B - Unclear \\
\hline
\end{tabular}

Kee 2001

\begin{tabular}{l|l}
\hline Methods & Method of randomization: not reported "patients were randomly assigned”. \\
Number randomized: 32 (16 to each arm). \\
Exclusions after randomization (total and per group): none. \\
Losses to follow up: none reported. \\
Method of allocation concealment: not reported. 1 surgeon performed all surgeries and \\
postoperative examinations. \\
Outcome assessor masking: Outcome assessment was not masked.
\end{tabular}

Cochrane Database Syst Rev. Author manuscript; available in PMC 2015 January 13. 


\begin{tabular}{|c|c|c|}
\hline & \multicolumn{2}{|c|}{$\begin{array}{l}\text { Intention-to-treat analysis: unclear. } \\
\text { Unusual study design: none. }\end{array}$} \\
\hline Participants & \multicolumn{2}{|c|}{$\begin{array}{l}\text { Age: Mean (SD) } 55.3 \text { (12.6) years in Ahmed implant with partial ligation arm; } 58.9 \text { (13.1) } \\
\text { years in Ahmed implant without ligation arm. } \\
\text { Sex: no data provided. } \\
\text { Inclusion criteria: high IOP not responding to medical treatment, laser surgery or prior } \\
\text { conventional surgery. } \\
\text { Exclusion criteria: no exclusion criteria reported. } \\
\text { Equivalence of baseline characteristics: mean age and diagnosis in participants were similar } \\
\text { at baseline in the } 2 \text { arms. } \\
\text { Diagnoses in participants: neovascular glaucoma; secondary glaucoma; aphakic glaucoma; } \\
\text { previous failed trabeculectomy. }\end{array}$} \\
\hline Interventions & \multicolumn{2}{|c|}{$\begin{array}{l}\text { Treatment: Ahmed valve implant with partial ligation of the tube. } \\
\text { Control: Ahmed valve implant, no ligation of the tube. } \\
\text { Postoperative treatment included topical } 0.3 \% \text { ofloxacin and } 1 \% \text { prednisolone acetate eye } \\
\text { drops four times a day for } 4 \text { weeks. }\end{array}$} \\
\hline Outcomes & \multicolumn{2}{|c|}{$\begin{array}{l}\text { IOP control; incidence of hypotony defined as IOP }<=5 \mathrm{~mm} \mathrm{Hg} \text { on any single visit. } \\
\text { Complete success: IOP }<22 \mathrm{~mm} \mathrm{Hg} \text { and }>5 \mathrm{~mm} \mathrm{Hg} \text { for the last two visits without } \\
\text { additional glaucoma surgery and without anti-glaucoma medications. } \\
\text { Qualified success: } \mathrm{IOP}<22 \mathrm{~mm} \mathrm{Hg} \text { and }>5 \mathrm{~mm} \mathrm{Hg} \text { with the use of anti-glaucoma } \\
\text { medications. } \\
\text { Failure: } \mathrm{IOP}>22 \mathrm{~mm} \mathrm{Hg} \text { or greater on maximally tolerated anti-glaucoma medications or } \\
\text { that requiring additional glaucoma surgery. }\end{array}$} \\
\hline Notes & \multicolumn{2}{|c|}{$\begin{array}{l}\text { Country and period of study: Korea, January } 1999 \text { to March } 2000 \text {. } \\
\text { Follow-up intervals: patients were examined on postoperative day } 1 \text { and "regularly } \\
\text { thereafter by one doctor". Analysis of data at } 6 \text { months of follow up was presented in the } \\
\text { paper. }\end{array}$} \\
\hline \multicolumn{3}{|l|}{ Risk of bias } \\
\hline Item & Authors' judgement & Description \\
\hline Allocation concealment? & Unclear & B - Unclear \\
\hline
\end{tabular}

\section{Lima 2004}

\begin{tabular}{|c|c|}
\hline Methods & $\begin{array}{l}\text { Method of randomization: not reported "participants were randomly assigned". } \\
\text { Number randomized: } 32 \text { (16 to each arm). } \\
\text { Exclusions after randomization (total and per group): none. } \\
\text { Losses to follow up: none reported. } \\
\text { Method of allocation concealment: not reported. One surgeon performed all surgeries and } \\
\text { postoperative examinations. } \\
\text { Outcome assessor masking: outcome assessment was not masked. } \\
\text { Intention-to-treat analysis: unclear. } \\
\text { Unusual study design: none. }\end{array}$ \\
\hline Participants & $\begin{array}{l}\text { Age: mean (SD) } 56.64 \text { (11.33) years in Ahmed implant arm; } 53.76 \text { (10.4) years in ECP } \\
\text { arm. } \\
\text { Sex: } 44 \% \text { in Ahmed implant arm and } 41 \% \text { in ECP arm were females. } \\
\text { Inclusion criteria: pseudophakic eyes with an IOP >/= } 35 \mathrm{~mm} \text { Hg on maximum tolerated } \\
\text { therapy; at least one previous trabeculectomy with antimetabolite; visual acuity better than } \\
\text { light perception. } \\
\text { Exclusion criteria: previous glaucoma drainage device implantation; prior cyclodestructive } \\
\text { procedure; no light perception; retinal or choroidal detachment; failed corneal graft. } \\
\text { Equivalence of baseline characteristics: age; race; gender; preoperative IOP; exposure to } \\
\text { antimetabolite; type of glaucoma similar in the two arms at baseline. } \\
\text { Diagnoses in participants: neovascular glaucoma; pseudophakic glaucoma; glaucoma } \\
\text { associated with penetrating keratoplasty; glaucoma associated with vitreoretinal surgery. }\end{array}$ \\
\hline Interventions & $\begin{array}{l}\text { Treatment: Ahmed valve implant. } \\
\text { Control: ECP. } \\
\text { All procedures in both arms were followed by subconjunctival injection of tobramycin and } \\
\text { dexamethasone. Additionally, } 0.1 \mathrm{ml} \text { of dexamethasone was injected in the anterior } \\
\text { chamber. Topical antibiotics, corticosteroids and atropine were prescribed postoperatively } \\
\text { and tapered as the intraocular inflammation decreased. }\end{array}$ \\
\hline Outcomes & $\begin{array}{l}\text { IOP control reported as final mean IOP and also as success and failure; visual acuity } \\
\text { (LogMAR method). }\end{array}$ \\
\hline
\end{tabular}

Cochrane Database Syst Rev. Author manuscript; available in PMC 2015 January 13. 
Success: IOP between 6 and $21 \mathrm{~mm} \mathrm{Hg}$ at 24 months of follow up with or without maximum tolerated therapy.

Failure: IOP > $21 \mathrm{~mm} \mathrm{Hg}$ during 3 consecutive postoperative visits; IOP below $6 \mathrm{~mm} \mathrm{Hg}$ for 60 days or more; necessity for another surgical intervention to control IOP.

\begin{tabular}{l|l|l}
\hline Notes & \multicolumn{2}{l}{$\begin{array}{l}\text { Country and period of study: Brazil. January 1998 to April 2000 } \\
\text { Follow-up intervals: Postoperative day 7, months 1,2,3,4, 5, 6, 12,18 and 24 }\end{array}$} \\
\hline Risk of bias & Authors' judgement & Description \\
\hline Item & C - Inadequate \\
\hline Allocation concealment? & No &
\end{tabular}

\section{Smith 1992}

\begin{tabular}{|c|c|}
\hline Methods & $\begin{array}{l}\text { Method of randomization: "randomized" - method of randomization was not reported. } \\
\text { Number randomized: } 40 \text { eyes ( } 19 \text { to Double plate Molteno implant and } 21 \text { to Schocket } \\
\text { shunt). } \\
\text { Exclusions after randomization (total and per group): none. } \\
\text { Losses to follow up: none. } \\
\text { Method of allocation concealment: not reported. } \\
\text { Outcome assessor masking: not reported. } \\
\text { Intention-to-treat analysis: yes. } \\
\text { Unusual study design: initially } 46 \text { eyes of } 40 \text { participants were randomized to the } 2 \\
\text { treatment arms. } 6 \text { participants who required bilateral surgery were randomized for the first } \\
\text { eye and the other eye received the alternate treatment. Since the } 2 \text { eyes cannot be } \\
\text { considered independent in the analysis, "three participants (three eyes) were assigned to } \\
\text { each group using a random digit table." }\end{array}$ \\
\hline Participants & $\begin{array}{l}\text { Age: not reported. } \\
\text { Sex: } 84 \% \text { in Molteno implant arm and } 62 \% \text { in ACTSEB arm were females. } \\
\text { Inclusion criteria: eyes with refractory glaucoma requiring surgery irrespective of type of } \\
\text { glaucoma except the congenital variety. } \\
\text { Exclusion criteria: children with congenital glaucoma; patients undergoing simultaneous } \\
\text { penetrating keratoplasty and drainage tube procedure. } \\
\text { Equivalence of baseline characteristics: mean IOP; glaucoma medications; types of } \\
\text { glaucoma similar at baseline. } \\
\text { Diagnoses in participants: aphakia/pseudophakia; prior unsuccessful glaucoma filter } \\
\text { surgery; uveitic glaucoma; neovascular glaucoma; glaucoma following penetrating } \\
\text { keratoplasty; glaucoma associated with congenital rubella syndrome (aphakic). }\end{array}$ \\
\hline Interventions & $\begin{array}{l}\text { Treatment: Double-plate Molteno implant. } \\
\text { Control: ACTSEB /Schocket procedure. } \\
\text { All participants received topical prednisolone acetate }(1 \%) \text { and topical tobramycin in the } \\
\text { early postoperative period. }\end{array}$ \\
\hline Outcomes & $\begin{array}{l}\text { IOP control reported as final mean IOP; mean } \\
\text { change in IOP; number of postoperative } \\
\text { medications; decrease in visual acuity. }\end{array}$ \\
\hline Notes & $\begin{array}{l}\text { Country and period of study: USA, } 1987 \text { to } 1989 \\
\text { Follow-up intervals: day 1, day } 2 \text {, weeks } 1,2,3 \text {, months } 1,3,6 \text { and every } 3 \text { to } 6 \text { months } \\
\text { thereafter. Mean (SD) of follow up was } 22.89 \text { (9.68) months for Molteno implant arm and } \\
29.10 \text { (13.30) months for ACTSEB/Schocket procedure arm. }\end{array}$ \\
\hline \multicolumn{2}{|l|}{ Risk of bias } \\
\hline Item & Authors' judgement \\
\hline Allocation concealment? & B - Unclear \\
\hline
\end{tabular}

\section{Susanna 2003}

Methods

Method of randomization: the first patient was assigned to treatment with a coin flip. Rest of participants were alternated consecutively to either treatment arm.

Number randomized: 92 (45 to S-2 high pressure Ahmed valve with resection of Tenon's capsule and 47 to Standard Ahmed valve without Tenon's resection).

Exclusions after randomization (total and per group): none. 


\begin{tabular}{|c|c|c|}
\hline & \multicolumn{2}{|c|}{$\begin{array}{l}\text { Losses to follow up: } 20 \text { patients in Ahmed valve with Tenon's capsule resection and } 14 \\
\text { patients in control group were lost to follow up at } 12 \text { months. Reasons were not reported. } \\
\text { Method of allocation concealment: Not possible due to alternating assignment. } \\
\text { Outcome assessor masking: not reported. } \\
\text { Intention-to-treat analysis: no. Patients lost to follow up were excluded from the analysis. } \\
\text { Unusual study design: none. }\end{array}$} \\
\hline Participants & \multicolumn{2}{|c|}{$\begin{array}{l}\text { Age: mean (SD) } 60.6 \text { (12.1) years in Ahmed valve with resection of Tenon's capsule arm; } \\
60.7 \text { (12.2) years in control arm. } \\
\text { Sex: } 44.4 \% \text { in Ahmed valve with resection of Tenon's capsule arm and } 46.8 \% \text { in control } \\
\text { arm were females. } \\
\text { Inclusion criteria: neovascular glaucoma without previous surgery; visual acuity of light } \\
\text { perception or better; neovascular glaucoma associated with CRVO or diabetes. } \\
\text { Exclusion criteria: no light perception; neovascular glaucoma with previous surgery; } \\
\text { neovascular glaucoma not associated with CRVO or diabetes. } \\
\text { Equivalence of baseline characteristics: age; gender; race; etiology of glaucoma; prior PRP } \\
\text { and preoperative IOP were similar at baseline in both treatment arms. } \\
\text { Diagnoses in participants: neovascular glaucoma. }\end{array}$} \\
\hline Interventions & \multicolumn{2}{|c|}{$\begin{array}{l}\text { Treatment: High-pressure Ahmed valve with resection of Tenon's capsule. } \\
\text { Control: Standard Ahmed valve. } \\
\text { All eyes in both treatment arms were administered topical } 1 \mathrm{mg} / \mathrm{ml} \text { MMC for } 3 \text { minutes, } \\
\text { placed below the Tenon's capsule at the site of insertion of the polypropylene reservoir. All } \\
\text { eyes received a scleral patch graft, subconjunctival injections of steroids and antibiotics. }\end{array}$} \\
\hline Outcomes & \multicolumn{2}{|c|}{$\begin{array}{l}\text { IOP control reported as final mean IOP and also as success; occurrence of postoperative } \\
\text { hypertensive phase; type of bleb (ischemic or non-ischemic). } \\
\text { Success: IOP }>4 \mathrm{~mm} \mathrm{Hg} \text { and }<22 \mathrm{~mm} \mathrm{Hg} \text { and at least } 30 \% \text { reduction from preoperative } \\
\text { values. }\end{array}$} \\
\hline Notes & \multicolumn{2}{|c|}{$\begin{array}{l}\text { Country and period of study: Brazil, Argentina, Columbia, Peru. January } 2000 \text { to December } \\
2000 . \\
\text { Follow-up intervals: postoperative days } 1 \text { and 10, months } 1,3,6 \text { and one year. }\end{array}$} \\
\hline \multicolumn{3}{|l|}{ Risk of bias } \\
\hline Item & Authors' judgement & Description \\
\hline Allocation concealment? & No & $\mathrm{C}$ - Inadequate \\
\hline
\end{tabular}

\section{Valimaki 1999}

Methods
Method of randomization: the first patient was assigned to treatment with a coin flip. Rest of participants were alternated consecutively to either treatment arm.

Number randomized: 92 (45 to S-2 high pressure Ahmed valve with resection of Tenon's capsule and 47 to Standard Ahmed valve without Tenon's resection).

Exclusions after randomization (total and per group): none.

Losses to follow up: 20 participants in Ahmed valve with Tenon's capsule resection and 14 participants in control group were lost to follow up at 12 months. Reasons were not reported.

Method of allocation concealment: Not possible due to alternating assignment

Outcome assessor masking: not reported.

Intention-to-treat analysis: no. Participants lost to follow up were excluded from the analysis.

Unusual study design: none. 
Participants

\begin{tabular}{|c|c|c|}
\hline & \multicolumn{2}{|c|}{$\begin{array}{l}\text { years in control arm. } \\
\text { Sex: } 30 \% \text { in Molteno implant with oral corticosteroids and } 64 \% \text { in control arm were } \\
\text { females. } \\
\text { Inclusion criteria: patients older than } 25 \text { years of age; no history of any type of } \\
\text { corticosteroid treatment within } 2 \text { weeks of surgery; high risk of filtration failure (failed } \\
\text { conventional glaucoma surgery, neovascular, traumatic, uveitic glaucoma); progressing or } \\
\text { likely to progress visual function status at current level of IOP on maximal-tolerated } \\
\text { medical and laser treatment. } \\
\text { Exclusion criteria: diabetes mellitus; congestive heart failure; gastric or duodenal ulcer } \\
\text { disease; history of psychiatric disease or active infection; regular use of NSAIDs; pregnant } \\
\text { or nursing women; women on inadequate contraception; patients who underwent argon } \\
\text { laser trabeculoplasty or any type of ocular surgery within } 6 \text { months prior to enrollment. } \\
\text { Equivalence of baseline characteristics: age of participants appears to differ in the } 2 \\
\text { treatment arms. } \\
\text { Diagnoses in participants: primary open-angle glaucoma; exfoliative glaucoma; } \\
\text { neovascular glaucoma; uveitic glaucoma; traumatic and juvenile glaucoma. }\end{array}$} \\
\hline Interventions & \multicolumn{2}{|c|}{$\begin{array}{l}\text { Treatment: Single-plate, single-stage Molteno implant with postoperative oral } \\
\text { corticosteroids, started on } 14 \text { th postoperative day. Oral steroids were given for } 10 \text { weeks } \\
(60 \mathrm{mg} \text { on days } 1 \text { to } 3,50 \mathrm{mg} \text { on days } 4 \text { to } 6,40 \mathrm{mg} \text { on days } 7 \text { to } 9,30 \mathrm{mg} \text { on days } 10 \text { to } 12 \text {, } \\
25 \mathrm{mg} \text { on days } 13 \text { to } 14,15 \mathrm{mg} \text { on days } 29 \text { to } 42,10 \mathrm{mg} \text { on days } 43 \text { to } 56,7.5 \mathrm{mg} \text { on days } \\
57 \text { to } 63 \text { and } 5 \mathrm{mg} \text { on days } 64 \text { to } 70 \text { ). } \\
\text { Control: Single plate, single stage, Molteno implant. } \\
\text { All participants in both arms were treated with topical chloramphenicol } 5 \text { times daily for } 12 \\
\text { weeks following surgery. }\end{array}$} \\
\hline Outcomes & \multicolumn{2}{|c|}{$\begin{array}{l}\text { Primary outcome: IOP control at } 6 \text { months. Success: IOP between } 6 \text { and } 22 \mathrm{~mm} \mathrm{Hg} \\
\text { inclusive with less than or as much anti-glaucoma medications as at the preoperative visit. } \\
\text { Secondary outcomes: serum marker studies for collagen synthesis (PICP and PIIINP). }\end{array}$} \\
\hline Notes & \multicolumn{2}{|c|}{$\begin{array}{l}\text { Country and period of study: Finland, August } 1995 \text { to February } 1997 . \\
\text { Follow-up intervals: postoperative day 1, weeks } 2,4,6,8,10,12,24 .\end{array}$} \\
\hline \multicolumn{3}{|l|}{ Risk of bias } \\
\hline Item & Authors' judgement & Description \\
\hline Allocation concealment? & Unclear & B - Unclear \\
\hline
\end{tabular}

\section{Wilson 1992}

\begin{tabular}{|c|c|}
\hline Methods & $\begin{array}{l}\text { Method of randomization: random number table was used. Randomization was stratified for } \\
\text { the following groups in blocks of 10: phakic, neovascular, aphakic or pseudophakic with } \\
\text { intact posterior lens capsule and pseudophakic without an intact posterior lens capsule. } \\
\text { Number randomized: } 134 \text { in total. Number of participants randomized to each group was } \\
\text { not reported. } \\
\text { Exclusions after randomization (total and per group): none. } \\
\text { Losses to follow up: } 6 \text { participants were lost to follow-up. Losses in each group not } \\
\text { reported and neither were the reasons for losses to follow-up. } \\
\text { Method of allocation concealment: "Type of treatment method selected was sealed in } \\
\text { sequentially numbered envelopes until needed." } \\
\text { Outcome assessor masking: outcome assessment was not masked as it was performed by } \\
\text { the "surgeon involved". However, the follow-up evaluation is reported to be standardized. } \\
\text { Intention-to-treat analysis: no. Data for } 9 \text { participants who did not yet complete } 6 \text { months of } \\
\text { follow up, } 6 \text { participants lost to follow-up and } 1 \text { patient with sympathetic ophthalmia were } \\
\text { not included. } \\
\text { Unusual study design: none. }\end{array}$ \\
\hline Participants & $\begin{array}{l}\text { Age: mean age } 58.2 \text { years in Molteno implant arm; } 59.1 \text { years in ACTSEB/Schocket } \\
\text { procedure arm. } \\
\text { Neither standard deviation nor range was reported. } \\
\text { Sex: } 55 \% \text { of participants in Molteno arm and } 56 \% \text { in ACTSEB/Schocket procedure arm } \\
\text { were females. } \\
\text { Inclusion criteria: uncontrolled IOP; prior unsuccessful filtration surgery with an } \\
\text { antifibrosis regimen diagnosis that would be expected to have poor response to filtration } \\
\text { surgery; private patient status. } \\
\text { Exclusion criteria: no explicit exclusion criteria were stated. } \\
\text { Equivalence of baseline characteristics: age; gender; diagnosis; and IOP similar at baseline. } \\
\text { Diagnoses in participants: aniridia; chronic angle-closure glaucoma (aphakia); chronic } \\
\text { open-angle glaucoma (aphakia); combined mechanism (phakic); congenital glaucoma; } \\
\text { inflammatory (phakic) glaucoma; ICE syndrome; neovascular glaucoma; primary angle- }\end{array}$ \\
\hline
\end{tabular}

Cochrane Database Syst Rev. Author manuscript; available in PMC 2015 January 13. 


\begin{tabular}{l|l|l} 
& $\begin{array}{l}\text { closure and primary open-angle glaucoma; pseudoexfoliation glaucoma; traumatic } \\
\text { glaucoma. }\end{array}$ \\
\hline Interventions & $\begin{array}{l}\text { Treatment: Double-plate Molteno implant. } \\
\text { Control: ACTSEB/Schocket procedure. }\end{array}$ \\
\hline Outcomes & $\begin{array}{l}\text { IOP control reported as final mean IOP; visual acuity; number of anti-glaucoma } \\
\text { medications; complications. }\end{array}$ \\
\hline Notes & $\begin{array}{l}\text { Country and period of study: USA. Study period not reported } \\
\text { Follow-up intervals: postoperative weeks 1, 2, months 1,3,6,9 and 12. The paper reported } \\
\text { analysis of data at 6 months only. }\end{array}$ \\
\hline Risk of bias & \multicolumn{2}{|l}{} \\
\hline Item & Authors' judgement & Description \\
\hline Allocation concealment? & Unclear & B - Unclear \\
\hline
\end{tabular}

\section{Wilson 2000}

\begin{tabular}{|c|c|}
\hline Methods & $\begin{array}{l}\text { Method of randomization: computer generated list of random numbers was used. } \\
\text { Number randomized: } 117 \text { ( } 62 \text { to Trabeculectomy and } 55 \text { to Ahmed implant). } \\
\text { Exclusions after randomization (total and per group): none. } \\
\text { Losses to follow up: } 16 \text { participants in Trabeculectomy arm and } 15 \text { in Ahmed implant arm } \\
\text { at } 11 \text { to } 13 \text { months. } \\
\text { Method of allocation concealment: not stated. } \\
\text { Outcome assessor masking: not reported. } \\
\text { Intention-to-treat analysis: not clear. Handling of participants lost to follow up was not } \\
\text { clearly reported. } \\
\text { Unusual study design: none. }\end{array}$ \\
\hline Participants & $\begin{array}{l}\text { Age: mean (SD) } 51.76 \text { (17.16) years for trabeculectomy arm; } 52.63 \text { (18.61) years for } \\
\text { Ahmed implant arm. } \\
\text { Sex: } 67 \% \text { in trabeculectomy arm and } 69 \% \text { in Ahmed implant arm were females. } \\
\text { Inclusion criteria: patients requiring glaucoma surgery for control of IOP. } \\
\text { Exclusion criteria: patients requiring combined surgery; unable or unwilling to maintain } \\
\text { follow up; age less than } 4 \text { years; eyes with a visual acuity of no light perception. } \\
\text { Equivalence of baseline characteristics: A higher proportion of eyes in trabeculectomy arm } \\
\text { were being treated with more than or equal to } 4 \text { medications at baseline. Visual acuity and } \\
\text { visual field scores were similar at baseline in the } 2 \text { arms. } \\
\text { Diagnoses in participants: primary open-angle and angle-closure glaucoma, neovascular } \\
\text { glaucoma, uveitic glaucoma and traumatic glaucoma. }\end{array}$ \\
\hline Interventions & $\begin{array}{l}\text { Treatment: Ahmed valve implant. } \\
\text { Control: trabeculectomy with administration of MMC left to the discretion of the surgeon. }\end{array}$ \\
\hline Outcomes & $\begin{array}{l}\text { Primary outcome: IOP control reported as final mean IOP } \\
\text { Secondary outcomes: Success defined as IOP }<21 \mathrm{~mm} \mathrm{Hg} \text { and at least a } 15 \% \text { reduction } \\
\text { from baseline, IOP }>5 \mathrm{~mm} \mathrm{Hg} \text { and no loss of light perception of visual acuity. } \\
\text { Other outcomes: visual acuity; visual field; cataract formation; anterior chamber depth; } \\
\text { glaucoma medication requirement; operative and postoperative complications }\end{array}$ \\
\hline Notes & $\begin{array}{l}\text { Country and period of study: Saudi Arabia, Colombo, Sri Lanka. Study period not reported. } \\
\text { Follow-up intervals: patients were examined on postoperative day 1, days } 7 \text { to } 14 \text {, weeks } 6 \\
\text { to } 15 \text {, months } 5 \text { to } 7 \text { and months } 11 \text { to } 13 \text {. }\end{array}$ \\
\hline \multicolumn{2}{|l|}{ Risk of bias } \\
\hline Item & Authors' judgement \\
\hline Allocation concealment? & B - Unclear \\
\hline
\end{tabular}

Wilson 2003

\begin{tabular}{l|l}
\hline Methods & $\begin{array}{l}\text { Method of randomization: computer-generated list of random numbers was used. } \\
\text { Number randomized: } 123 \text { (64 to Trabeculectomy and 59 to Ahmed implant). } \\
\text { Exclusions after randomization (total and per group): none. }\end{array}$
\end{tabular}

Cochrane Database Syst Rev. Author manuscript; available in PMC 2015 January 13. 


\begin{tabular}{|c|c|c|}
\hline & \multicolumn{2}{|c|}{$\begin{array}{l}\text { Losses to follow up: } 6 \text { participants in Trabeculectomy arm and } 7 \text { in Ahmed implant arm } \\
\text { were lost to follow up by days } 7 \text { to } 14 \text {. Losses to follow up at } 11 \text { to } 13 \text { months were not } \\
\text { reported. } \\
\text { Mean follow up (SD): } 31 \text { (10.6) months for Trabeculectomy arm; } 31 \text { (7.1) months for } \\
\text { Ahmed implant arm. } \\
\text { Method of allocation concealment: not reported. } \\
\text { Outcome assessor masking: not reported. } \\
\text { Intention-to-treat analysis: not clear. Handling of participants lost to follow up was not } \\
\text { clearly reported. } \\
\text { Unusual study design: none. }\end{array}$} \\
\hline Participants & \multicolumn{2}{|c|}{$\begin{array}{l}\text { Age: Mean (SD) } 51.92 \text { (16.39) years for Trabeculectomy arm; } 52.02 \text { (18.85) years for } \\
\text { Ahmed implant arm. } \\
\text { Sex: } 67 \% \text { in Trabeculectomy arm and } 70 \% \text { in Ahmed implant arm were females. } \\
\text { Inclusion criteria: primary open-angle or primary chronic angle-closure glaucoma requiring } \\
\text { surgical intervention. } \\
\text { Exclusion criteria: causes for glaucoma other than those stated in inclusion criteria; eyes } \\
\text { with prior intraocular surgery; eyes with visual acuity of no light perception; requirement } \\
\text { for combined surgery; age less than } 4 \text { years; inability to maintain follow up for a prolonged } \\
\text { period. } \\
\text { Equivalence of baseline characteristics: a higher proportion of eyes in trabeculectomy arm } \\
\text { were being treated with }>/=4 \text { medications at baseline. Visual acuity and visual field scores } \\
\text { were similar at baseline in the } 2 \text { arms. } \\
\text { Diagnoses in participants: primary open-angle glaucoma; primary chronic angle-closure } \\
\text { glaucoma. }\end{array}$} \\
\hline Interventions & \multicolumn{2}{|c|}{$\begin{array}{l}\text { Treatment: Single-plate Ahmed valve implant (Model S-2). } \\
\text { Control: trabeculectomy with administration of MMC left to the discretion of the surgeon. }\end{array}$} \\
\hline Outcomes & \multicolumn{2}{|c|}{$\begin{array}{l}\text { Primary outcome: IOP control reported as final mean IOP } \\
\text { Secondary outcomes: success defined as IOP }<21 \mathrm{~mm} \mathrm{Hg} \text { and at least a } 15 \% \text { reduction } \\
\text { from baseline, IOP }>5 \mathrm{~mm} \mathrm{Hg} \text {; no need for further glaucoma surgery; no loss of light } \\
\text { perception of visual acuity. } \\
\text { Other outcomes: decrease in visual acuity; progression of visual field; cataract formation; } \\
\text { anterior chamber depth; glaucoma medication requirement; operative and postoperative } \\
\text { complications. }\end{array}$} \\
\hline Notes & \multicolumn{2}{|c|}{$\begin{array}{l}\text { Country and period of study: Colombo, Sri Lanka. Study period not reported } \\
\text { Follow-up intervals: participants were examined on postoperative day } 1 \text {, days } 7 \text { to } 14 \text {, } \\
\text { weeks } 6 \text { to } 15 \text {, months } 5 \text { to } 7 \text {, months } 11 \text { to } 13 \text {, months } 14 \text { to } 18 \text {, months } 20 \text { to } 24 \text {, months } \\
25 \text { to } 30 \text {, months } 34 \text { to } 40 \text {, months } 41 \text { to } 46 \text { and months } 50 \text { to } 52 \text {. }\end{array}$} \\
\hline \multicolumn{3}{|l|}{ Risk of bias } \\
\hline Item & Authors' judgement & Description \\
\hline Allocation concealment? & Unclear & B - Unclear \\
\hline
\end{tabular}

ACTSEB: anterior chamber tube shunt to an encircling band (Schocket shunt)

BSS: balanced salt solution

CRVO: central retinal vein occlusion

ECP: endocyclophotocoagulation

HAD: hunan aqueous device

ICE syndrome: iridocorneal endothelial syndrome

IOP: intraocular pressure

MMC: mitomycin C

NSAIDs: non-steroidal anti-inflammatory drugs

PICP: carboxyterminal propeptide of type I procollagen

PIIINP: aminoterminal propeptide of type III procollagen

PRP: pan retinal photocoagulation

SD: standard deviation

Characteristics of excluded studies [ordered by study ID]

\begin{tabular}{|l|l|}
\hline Arroyave 2003 & Retrospective case series \\
\hline
\end{tabular}




\begin{tabular}{|c|c|}
\hline Ayyala 1998 & Retrospective case series \\
\hline Ayyala 2002 & Retrospective case series with concurrent controls \\
\hline Beck 2003 & Retrospective time series study with comparison group \\
\hline Benz 2002 & Retrospective case series \\
\hline Budenz 2002 & Retrospective case series \\
\hline Chen 1997 & Retrospective case series \\
\hline Coleman 1995 & Prospective case series \\
\hline Coleman 1997 & Prospective case series \\
\hline Djodeyre 2001 & Retrospective case series \\
\hline Eid 1997 & Retrospective case series with matched controls \\
\hline Francis 2005 & Prospective case series \\
\hline Hill 1991 & Consecutive case series \\
\hline Hill 2003 & Retrospective case series \\
\hline Hong 2005 & Review article \\
\hline Huang 1999 & Retrospective case series \\
\hline Kansal 2002 & $\begin{array}{l}\text { Prospective cohort study on patient comfort with different types of anesthesia in aqueous shunt } \\
\text { surgery }\end{array}$ \\
\hline KEVFSSG 1994 & Prospective case series \\
\hline Kim 2003 & Retrospective case series \\
\hline Lee 1997 & Retrospective case series with historical controls \\
\hline Leuenberger 1999 & Review article \\
\hline Lloyd 1992 & Prospective case series \\
\hline Lloyd 1994a & Prospective case series \\
\hline Luttrull 1995 & Retrospective case series \\
\hline Minckler 2001 & Review article \\
\hline Molteno 1969 & Prospective case series \\
\hline Molteno 2001a & Prospective case series \\
\hline Molteno 2001b & Prospective case series \\
\hline Morad 2003 & Retrospective case series \\
\hline Noureddin 1992 & Retrospective cohort study \\
\hline Nouri-Madhavi 2003 & Retrospective case series \\
\hline Pastor 2001 & Review article \\
\hline Paysse 1996 & Case control study \\
\hline Perkins 1995 & Prospective case series with historical controls \\
\hline Perkins 1998 & Prospective case series with historical controls \\
\hline Rapuano 1995 & Retrospective case series \\
\hline Saw 2003 & Review article \\
\hline Sayyad 1995 & Retrospective case series with historical controls \\
\hline Seah 2003 & Retrospective cohort study \\
\hline Shaikh 2002 & Prospective case series \\
\hline Sivak-Callcott 2001 & Review article \\
\hline
\end{tabular}




\begin{tabular}{l|l} 
Strum 1998 & Case series \\
\hline Taglia 1999 & Case report \\
\hline Topouzis 1999 & Prospective cohort study \\
\hline Tsai 2003 & Retrospective cohort study \\
\hline Tuli 2001 & Case control study \\
\hline Whittaker 2003 & Retrospective case series \\
\hline
\end{tabular}

\section{Characteristics of ongoing studies [ordered by study ID]}

\section{Gedde 2005}

\begin{tabular}{|c|c|}
\hline Trial name or title & The Tube versus Trabeculectomy Study \\
\hline \multicolumn{2}{|l|}{ Methods } \\
\hline Participants & $\begin{array}{l}\text { Age: Mean (SD) was } 70.9 \text { (11.0) years for 350-mm2 Baerveldt implant arm and } 71.1 \text { (9.9) years } \\
\text { for trabeculectomy arm } \\
\text { Sex: } 60 \% \text { in } 350 \mathrm{~mm} 2 \text { Baerveldt implant arm and } 46 \% \text { in trabeculectomy arm were females } \\
\text { Inclusion Criteria: Participants with inadequately controlled glaucoma with IOP greater than or } \\
\text { equal to } 18 \mathrm{~mm} \text { Hg but less than or equal to } 40 \mathrm{~mm} \text { Hg on tolerated medical therapy, and who } \\
\text { had previous trabeculectomy, cataract extraction with intraocular lens implantation or both } \\
\text { Exclusion Criteria: Participants requiring combined surgery, unable or unwilling to give } \\
\text { consent, accept randomization and maintain follow-up, pregnant and nursing women, eyes with } \\
\text { a visual acuity of no light perception, active iris neovascularization or active proliferative } \\
\text { retinopathy, iridocorneal endothelial syndrome, epithelial or fibrous downgrowth, aphakia, } \\
\text { chronic or recurrent uveitis, previous history of cyclodestructive procedure, scleral buckling } \\
\text { procedure, conjunctival scarring precluding a trabeculectomy superiorly, vitreous in the anterior } \\
\text { chamber for which a vitrectomy was anticipated, and severe posterior blepharitis } \\
\text { Equivalence of baseline characteristics: Participants in both treatment arms were similar at } \\
\text { baseline with respect to mean visual acuity, visual field, mean number of preoperative anti- } \\
\text { glaucoma medications, mean IOP, number of previous intraocular surgical procedures, and lens } \\
\text { status. A greater number of participants in the Baerveldt implant arm were females, had a } \\
\text { diagnosis of pseudoexfoliative glaucoma. A greater number of participants in the } \\
\text { trabeculectomy arm had a lower visual acuity due to cataract. } \\
\text { Diagnoses in participants: Primary open angle, chronic angle closure glaucoma, } \\
\text { pseudoexfoliative glaucoma, and other forms of glaucoma }\end{array}$ \\
\hline Interventions & $\begin{array}{l}\text { Treatment: } 350 \mathrm{~mm} 2 \text { Baerveldt implant } \\
\text { Control: Trabeculectomy with administration of Mitomycin C }(0.4 \mathrm{mg} / \mathrm{ml} \text { for } 4 \text { minutes })\end{array}$ \\
\hline Outcomes & $\begin{array}{l}\text { Primary outcome: Level of intraocular pressure; rate of complications } \\
\text { Secondary outcomes: Failure as defined by the following: IOP }>21 \mathrm{~mm} \text { Hg or not reduced by } \\
20 \% \text { below baseline on two consecutive follow-up visits after } 3 \text { months, IOP less than or equal } \\
\text { to } 5 \mathrm{~mm} \text { Hg on two consecutive follow-up visits after } 3 \text { months, additional glaucoma surgery, } \\
\text { loss of light perception. } \\
\text { Complete success: eyes that have not failed and are not on supplemental medical therapy, } \\
\text { Qualified success: eyes that have not failed but require supplemental medical therapy } \\
\text { Visual acuity } \\
\text { Visual field } \\
\text { Quality of life }\end{array}$ \\
\hline Starting date & October 1999 to April 2004 \\
\hline Contact information & Steven J. Gedde, MD, Bascom Palmer Eye Institute, 900 NW 17th Street, Miami, Florida 33136 \\
\hline Notes & $\begin{array}{l}\text { Country and period of study: USA } \\
\text { Study period: October } 1999 \text { to April } 2004 \\
\text { Follow up intervals: Patients were examined on postoperative day 1, week 1, months 3, 6, 12, } \\
18 \text {, years } 2,3,4 \text {, and } 5\end{array}$ \\
\hline
\end{tabular}




\section{Data and Analyses}

\section{Comparison 1. Ahmed implant versus trabeculectomy}

\begin{tabular}{lcccc}
\hline $\begin{array}{l}\text { Outcome or subgroup } \\
\text { title }\end{array}$ & No. of studies & No. of participants & Statistical method & Effect size \\
\hline $\begin{array}{l}1 \text { Mean intraocular } \\
\text { pressure at 11 to 13 } \\
\text { months follow up }\end{array}$ & 2 & 195 & $\begin{array}{c}\text { Mean Difference (IV, } \\
\text { Fixed, 95\% CI) }\end{array}$ & $-3.81[-5.69,-1.94]$ \\
\hline
\end{tabular}

\section{Comparison 2. Ahmed implant versus endocyclophotocoagulation (ECP)}

\begin{tabular}{|c|c|c|c|c|}
\hline $\begin{array}{l}\text { Outcome or subgroup } \\
\text { title }\end{array}$ & No. of studies & No. of participants & Statistical method & Effect size \\
\hline $\begin{array}{l}1 \text { Mean intraocular } \\
\text { pressure }\end{array}$ & 1 & & $\begin{array}{l}\text { Mean Difference (IV, Fixed, } \\
95 \% \mathrm{CI})\end{array}$ & Totals not selected \\
\hline $\begin{array}{l}\text { 1.1 At 12-months } \\
\text { follow-up }\end{array}$ & 1 & & $\begin{array}{l}\text { Mean Difference (IV, Fixed, } \\
95 \% \mathrm{CI})\end{array}$ & Not estimable \\
\hline $\begin{array}{l}\text { 1.2 At 24-months } \\
\text { follow-up }\end{array}$ & 1 & & $\begin{array}{l}\text { Mean Difference (IV, Fixed, } \\
95 \% \mathrm{CI})\end{array}$ & Not estimable \\
\hline $\begin{array}{l}2 \text { Mean } \log \text { MAR visual } \\
\text { acuity at } 24 \text { months } \\
\text { follow up }\end{array}$ & 1 & & $\begin{array}{l}\text { Mean Difference (IV, Fixed, } \\
95 \% \text { CI) }\end{array}$ & Totals not selected \\
\hline $\begin{array}{l}3 \text { Anti-glaucoma } \\
\text { medications at } 24 \\
\text { months follow up }\end{array}$ & 1 & & $\begin{array}{l}\text { Mean Difference (IV, Fixed, } \\
95 \% \mathrm{CI})\end{array}$ & Totals not selected \\
\hline
\end{tabular}

Comparison 3. Ahmed implant with MMC versus

Ahmed implant with balanced salt solution (BSS)

\begin{tabular}{|c|c|c|c|c|}
\hline $\begin{array}{l}\text { Outcome or subgroup } \\
\text { title }\end{array}$ & No. of studies & No. of participants & Statistical method & Effect size \\
\hline $\begin{array}{l}1 \text { Mean intraocular } \\
\text { pressure at } 12 \text { months } \\
\text { follow up }\end{array}$ & 1 & & $\begin{array}{l}\text { Mean Difference (IV, } \\
\text { Fixed, 95\% CI) }\end{array}$ & Totals not selected \\
\hline $\begin{array}{l}2 \text { Anti-glaucoma } \\
\text { medications at } 12 \text { months } \\
\text { follow up }\end{array}$ & 1 & & $\begin{array}{l}\text { Mean Difference (IV, } \\
\text { Fixed, 95\% CI) }\end{array}$ & Totals not selected \\
\hline
\end{tabular}

Comparison 4. High-pressure Ahmed implant + MMC

+ partial Tenon capsule resection versus Standard

Ahmed implant + MMC

\begin{tabular}{lcccc}
\hline $\begin{array}{l}\text { Outcome or subgroup } \\
\text { title }\end{array}$ & No. of studies & No. of participants & Statistical method & Effect size \\
\hline $\begin{array}{l}\text { 1 Mean intraocular } \\
\text { pressure at 12 months } \\
\text { follow up }\end{array}$ & 1 & $\begin{array}{c}\text { Mean Difference (IV, } \\
\text { Fixed, 95\% CI) }\end{array}$ & Totals not selected \\
\hline
\end{tabular}




\section{Comparison 5. Double-plate Molteno implant versus Schocket shunt}

\begin{tabular}{lcccc}
\hline $\begin{array}{l}\text { Outcome or subgroup } \\
\text { title }\end{array}$ & No. of studies & No. of participants & Statistical method & Effect size \\
\hline $\begin{array}{l}\text { 1 Mean intraocular } \\
\text { pressure at six months } \\
\text { follow up }\end{array}$ & 2 & $\begin{array}{c}\text { Mean Difference (IV, } \\
\text { Fixed, 95\% CI) }\end{array}$ & Totals not selected \\
\hline
\end{tabular}

\section{Comparison 6. Single-plate Molteno implant with oral corticosteroids versus single-plate Molteno implant alone}

\begin{tabular}{|c|c|c|c|c|}
\hline Outcome or subgroup title & No. of studies & No. of participants & Statistical method & Effect size \\
\hline $\begin{array}{l}1 \text { Mean intraocular pressure at } \\
\text { six months follow up }\end{array}$ & 1 & & $\begin{array}{l}\text { Mean Difference } \\
\text { (IV, Fixed, 95\% CI) }\end{array}$ & Totals not selected \\
\hline 2 Visual acuity & 1 & & $\begin{array}{l}\text { Risk Ratio (M-H, } \\
\text { Fixed, 95\% CI) }\end{array}$ & Totals not selected \\
\hline $\begin{array}{l}\text { 2.1 Stable vision - visual } \\
\text { acuity unchanged or within one } \\
\text { line from baseline }\end{array}$ & 1 & & $\begin{array}{l}\text { Risk Ratio (M-H, } \\
\text { Fixed, 95\% CI) }\end{array}$ & Not estimable \\
\hline $\begin{array}{l}2.2 \text { Loss of vision - loss of } 2 \\
\text { or more lines from baseline }\end{array}$ & 1 & & $\begin{array}{l}\text { Risk Ratio (M-H, } \\
\text { Fixed, 95\% CI) }\end{array}$ & Not estimable \\
\hline 3 Anti-glaucoma medications & 1 & & $\begin{array}{l}\text { Mean Difference } \\
\text { (IV, Fixed, 95\% CI) }\end{array}$ & Totals not selected \\
\hline
\end{tabular}

Comparison 7. Double-plate Molteno implant + MMC versus Molteno implant + balanced salt solution (BSS)

\begin{tabular}{|c|c|c|c|c|}
\hline $\begin{array}{l}\text { Outcome or subgroup } \\
\text { title }\end{array}$ & No. of studies & No. of participants & Statistical method & Effect size \\
\hline $\begin{array}{l}1 \text { Mean intraocular } \\
\text { pressure at } 12 \text { months } \\
\text { follow up }\end{array}$ & 1 & & $\begin{array}{l}\text { Mean Difference (IV, } \\
\text { Fixed, 95\% CI) }\end{array}$ & Totals not selected \\
\hline $\begin{array}{l}2 \text { Mean logMAR visual } \\
\text { acuity at } 12 \text { months } \\
\text { follow up }\end{array}$ & 1 & & $\begin{array}{l}\text { Mean Difference (IV, } \\
\text { Fixed, 95\% CI) }\end{array}$ & Totals not selected \\
\hline $\begin{array}{l}3 \text { Anti-glaucoma } \\
\text { medications at } 12 \text { months } \\
\text { follow up }\end{array}$ & 1 & & $\begin{array}{l}\text { Mean Difference (IV, } \\
\text { Fixed, 95\% CI) }\end{array}$ & Totals not selected \\
\hline
\end{tabular}

\section{Comparison 8. Single-plate Molteno implant versus double-plate Molteno implant}

\begin{tabular}{lcccc}
\hline $\begin{array}{l}\text { Outcome or subgroup } \\
\text { title }\end{array}$ & No. of studies & No. of participants & Statistical method & Effect size \\
\hline $\begin{array}{l}\text { 1 IOP outcomes at final } \\
\text { follow up }\end{array}$ & 1 & Risk Ratio (M-H, Fixed, & Totals not selected \\
$95 \%$ CI) & &
\end{tabular}




\begin{tabular}{|c|c|c|c|c|}
\hline $\begin{array}{l}\text { Outcome or subgroup } \\
\text { title }\end{array}$ & No. of studies & No. of participants & Statistical method & Effect size \\
\hline $\begin{array}{l}1.1 \text { Success (final IOP } \\
\text { not greater than } 21 \mathrm{~mm} \mathrm{Hg} \\
\text { and at least a } 30 \% \\
\text { reduction from baseline) }\end{array}$ & 1 & & $\begin{array}{r}\text { Risk Ratio (M-H, Fixed, } \\
95 \% \mathrm{CI})\end{array}$ & Not estimable \\
\hline $\begin{array}{l}1.2 \text { Complete success } \\
\text { (final IOP not greater than } \\
21 \mathrm{~mm} \mathrm{Hg} \text { without } \\
\text { additional anti-glaucoma } \\
\text { medications) }\end{array}$ & 1 & & $\begin{array}{r}\text { Risk Ratio (M-H, Fixed, } \\
95 \% \mathrm{CI})\end{array}$ & Not estimable \\
\hline $\begin{array}{l}1.3 \text { Qualified success } \\
\text { (final IOP not greater than } \\
21 \mathrm{~mm} \mathrm{Hg} \text { and on } \\
\text { adjunctive anti-glaucoma } \\
\text { medications) }\end{array}$ & 1 & & $\begin{array}{r}\text { Risk Ratio (M-H, Fixed, } \\
95 \% \mathrm{CI})\end{array}$ & Not estimable \\
\hline
\end{tabular}

Comparison 9. $350 \mathrm{~mm} 2$ Baerveldt implant versus 500 mm2 Baerveldt implant

\begin{tabular}{|c|c|c|c|c|}
\hline $\begin{array}{l}\text { Outcome or subgroup } \\
\text { title }\end{array}$ & No. of studies & No. of participants & Statistical method & Effect size \\
\hline $\begin{array}{l}1 \text { Mean intraocular } \\
\text { pressure }\end{array}$ & 1 & & $\begin{array}{l}\text { Mean Difference (IV, Fixed, } \\
95 \% \mathrm{CI})\end{array}$ & Totals not selected \\
\hline $\begin{array}{l}\text { 1.1 At } 12 \text { months } \\
\text { follow up }\end{array}$ & 1 & & $\begin{array}{l}\text { Mean Difference (IV, Fixed, } \\
95 \% \mathrm{CI})\end{array}$ & Not estimable \\
\hline $\begin{array}{l}1.2 \text { At } 2 \text { years follow } \\
\text { up }\end{array}$ & 1 & & $\begin{array}{l}\text { Mean Difference (IV, Fixed, } \\
95 \% \mathrm{CI})\end{array}$ & Not estimable \\
\hline $\begin{array}{l}1.3 \text { At } 3 \text { years follow } \\
\text { up }\end{array}$ & 1 & & $\begin{array}{l}\text { Mean Difference (IV, Fixed, } \\
95 \% \mathrm{CI})\end{array}$ & Not estimable \\
\hline up 1.4 At 4 years follow & 1 & & $\begin{array}{l}\text { Mean Difference (IV, Fixed, } \\
95 \% \text { CI) }\end{array}$ & Not estimable \\
\hline up 1.5 At 5 years follow & 1 & & $\begin{array}{l}\text { Mean Difference (IV, Fixed, } \\
\text { 95\% CI) }\end{array}$ & Not estimable \\
\hline
\end{tabular}

Analysis 1.1. Comparison 1 Ahmed implant versus trabeculectomy, Outcome 1 Mean intraocular pressure at 11 to 13 months follow up

Review. Aqueous shunts for glaucoma

Comparison: I Ahmed implant versus trabeculectomy

Outcome: I Mean intraocular pressure at 11 to 13 months follow up

\begin{tabular}{|c|c|c|c|c|c|c|c|}
\hline \multirow[t]{2}{*}{ Study or subgroup } & \multicolumn{2}{|l|}{ Trabeculectomy } & \multicolumn{2}{|l|}{ Ahmed implant } & Mean Difference & \multirow[t]{2}{*}{ Weight } & \multirow{2}{*}{$\begin{array}{r}\text { Mean Difference } \\
\text { IV.Fixed,95\% C }\end{array}$} \\
\hline & N & Mean(SD) & $\mathrm{N}$ & $\operatorname{Mean}(\mathrm{SD})$ & IV.Fixed,95\% Cl & & \\
\hline Wilson 2000 & 46 & $11.42(5.93)$ & 40 & $17.17(8.7)$ & $=$ & $34.4 \%$ & $-5.75[-8.94,-2.56]$ \\
\hline Wilson 2003 & 57 & $13.8(4.72)$ & 52 & $16.6(7.21)$ & - & $65.6 \%$ & $-2.80[-5.11,-0.49]$ \\
\hline
\end{tabular}

Total $(95 \% \mathrm{CI}) \quad 103$

Heterogeneity: $\mathrm{Chi}^{2}=2.15, \mathrm{df}=1(\mathrm{P}=0.14): \mathrm{I}^{2}=53 \%$

Test for overall effect: $Z=3.99(P=0.000066)$

$100.0 \% \quad-3.81[-5.69,-1.94]$ 
Analysis 2.1. Comparison 2 Ahmed implant versus endocyclophotocoagulation (ECP), Outcome 1 Mean intraocular pressure

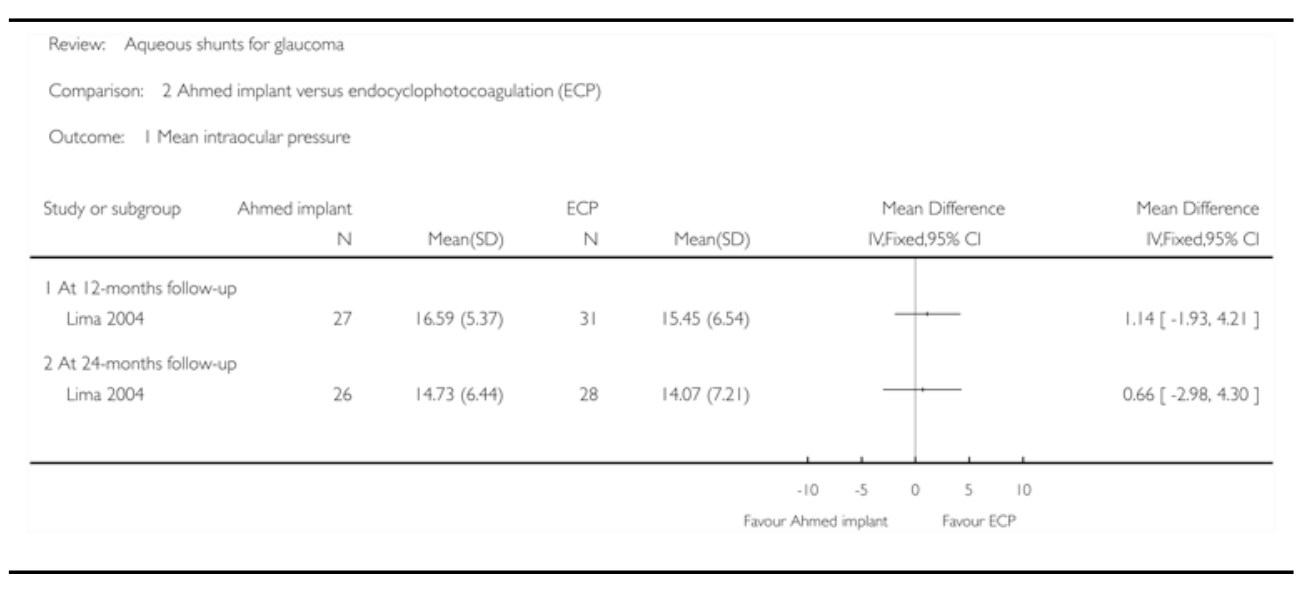

Analysis 2.2. Comparison 2 Ahmed implant versus endocyclophotocoagulation (ECP), Outcome 2 Mean $\log$ MAR visual acuity at 24 months follow up

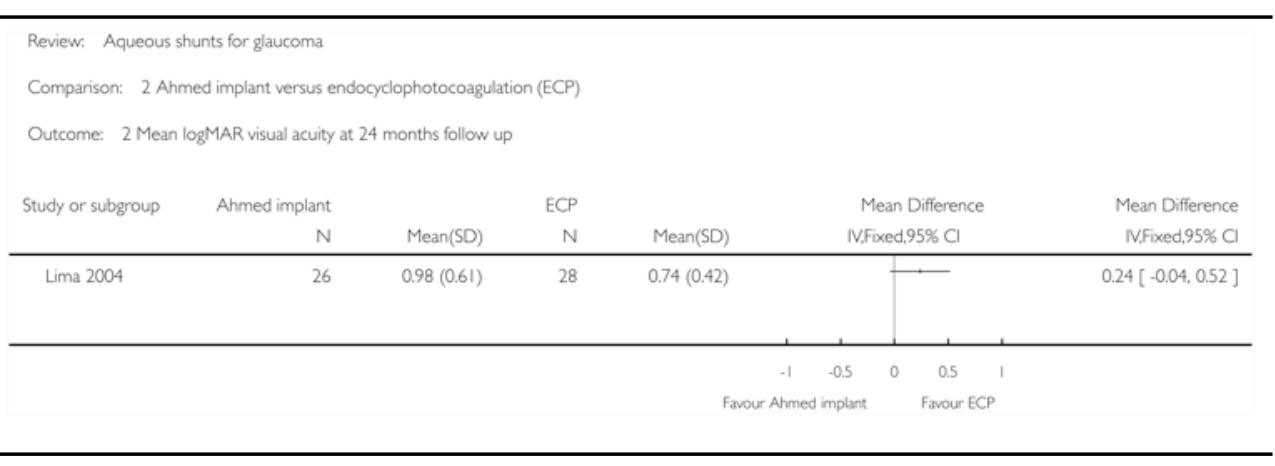


Analysis 2.3. Comparison 2 Ahmed implant versus endocyclophotocoagulation (ECP), Outcome 3 Antiglaucoma medications at 24 months follow up

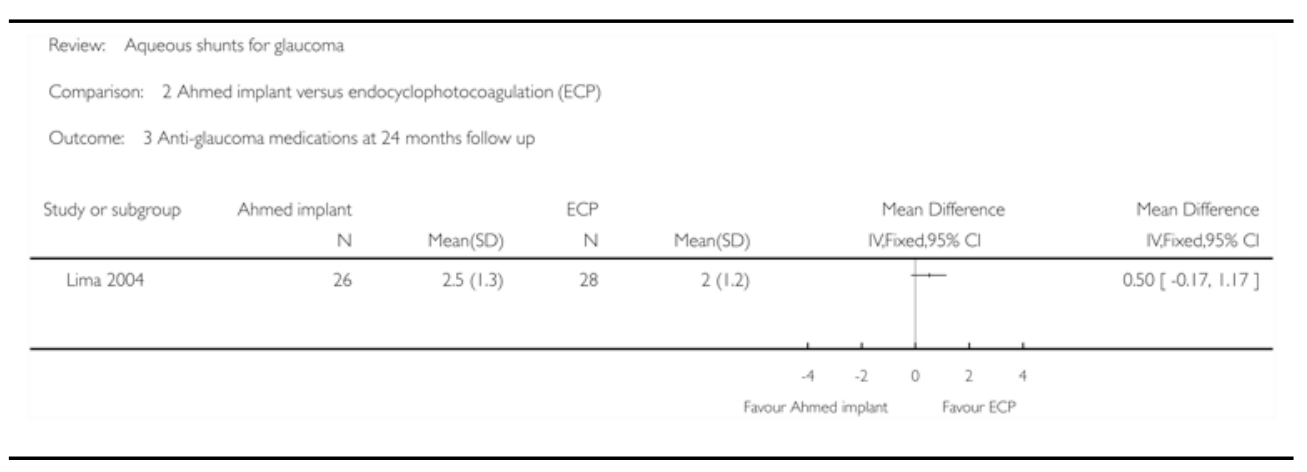

Analysis 3.1. Comparison 3 Ahmed implant with MMC versus Ahmed implant with balanced salt solution (BSS), Outcome 1 Mean intraocular pressure at 12 months follow up

\begin{tabular}{|c|c|c|c|c|c|c|c|}
\hline \multicolumn{8}{|c|}{ Review: Aqueous shunts for glaucoma } \\
\hline \multicolumn{8}{|c|}{ Comparison: 3 Ahmed implant with MMC versus Ahmed implant with balanced salt solution (BSS) } \\
\hline \multicolumn{8}{|c|}{ Outcome: 1 Mean intraocular pressure at 12 months follow up } \\
\hline \multirow[t]{2}{*}{ Study or subgroup } & Ahmed implant + MMC & & Ahmed implant + BSS & & \multicolumn{2}{|c|}{ Mean Difference } & Mean Difference \\
\hline & $\mathrm{N}$ & Mean(SD) & $\mathrm{N}$ & Mean(SD) & \multicolumn{2}{|c|}{ IV,Fixed,95\% Cl } & IV.Fixed.95\% CI \\
\hline \multirow[t]{3}{*}{ Costa 2004} & 19 & $15.1(4)$ & 13 & $15.3(3.5)$ & & 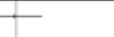 & $-0.20[-2.82,2.42]$ \\
\hline & \multirow{2}{*}{\multicolumn{7}{|c|}{$\begin{array}{ccccc}-10 & -5 & 0 & 5 & 10 \\
\text { Fapurs adung MMC } & \end{array}$}} \\
\hline & & & & Favoun & & & \\
\hline
\end{tabular}


Analysis 3.2. Comparison 3 Ahmed implant with MMC versus Ahmed implant with balanced salt solution (BSS), Outcome 2 Anti-glaucoma medications at 12 months follow up

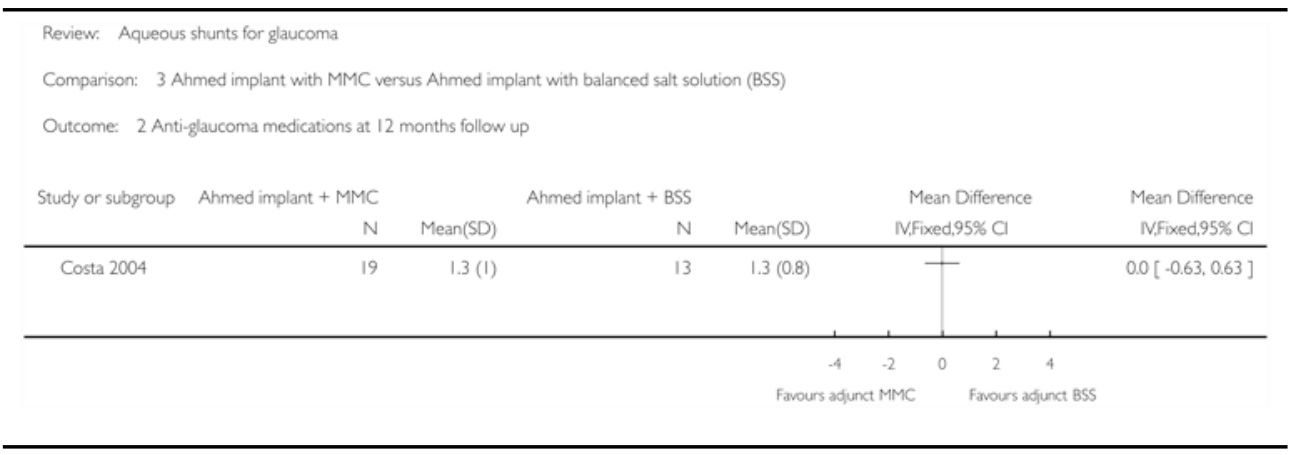

Analysis 4.1. Comparison 4 High-pressure Ahmed implant + MMC + partial Tenon capsule resection versus Standard Ahmed implant + MMC, Outcome 1 Mean intraocular pressure at 12 months follow up

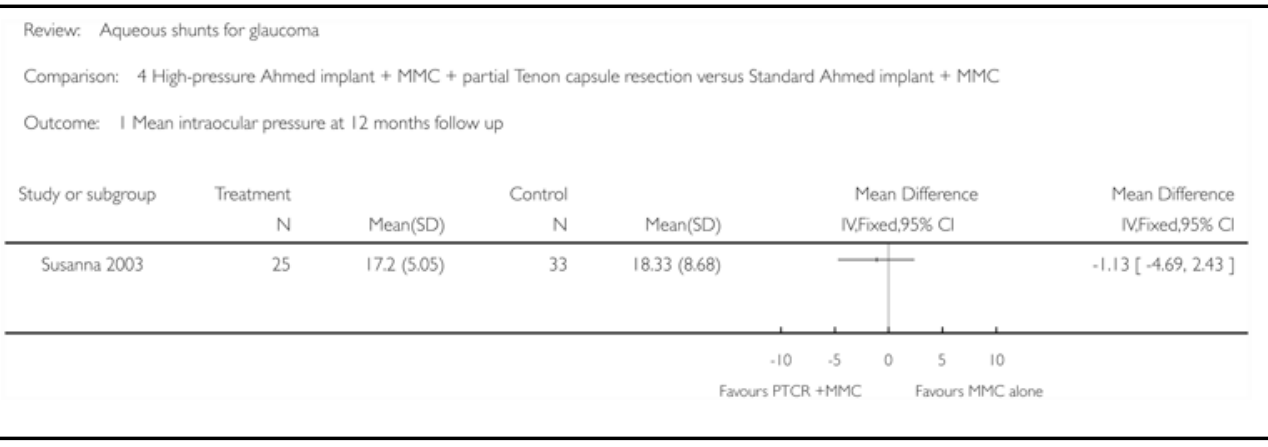


Analysis 5.1. Comparison 5 Double-plate Molteno implant versus Schocket shunt, Outcome 1 Mean intraocular pressure at six months follow up

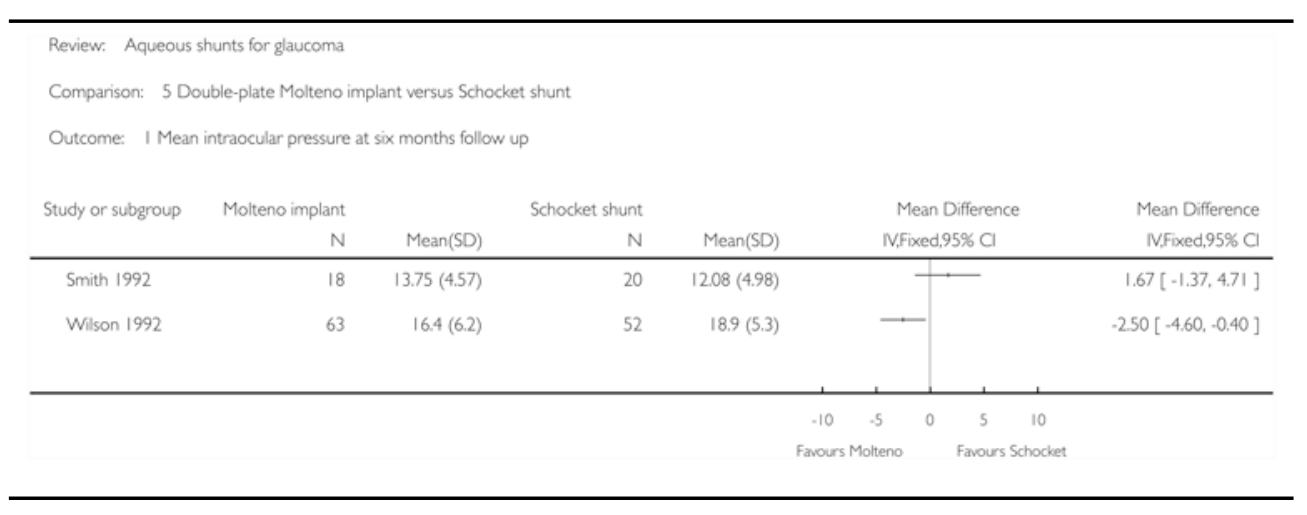

Analysis 6.1. Comparison 6 Single-plate Molteno implant with oral corticosteroids versus single-plate Molteno implant alone, Outcome 1 Mean intraocular pressure at six months follow up

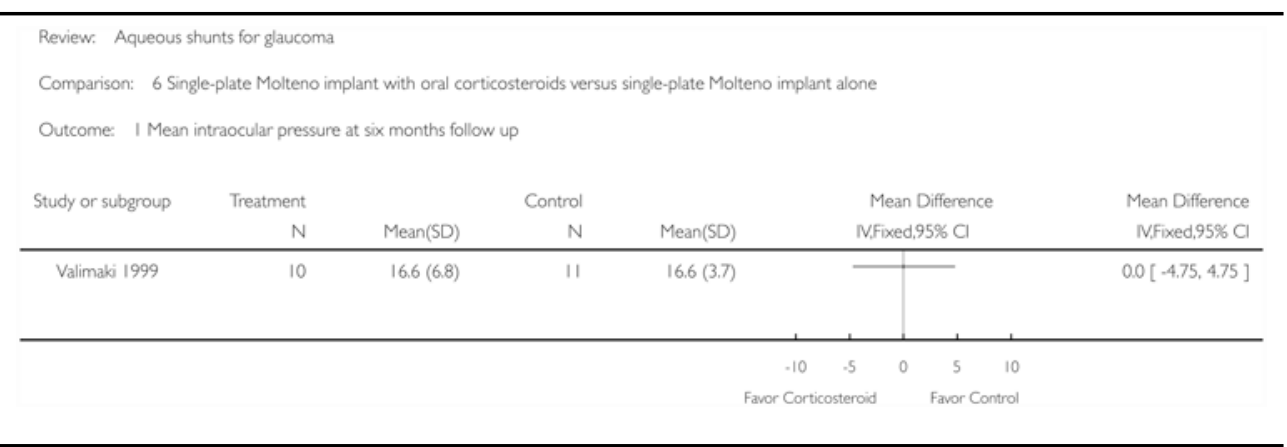


Analysis 6.2. Comparison 6 Single-plate Molteno implant with oral corticosteroids versus single-plate Molteno implant alone, Outcome 2 Visual acuity

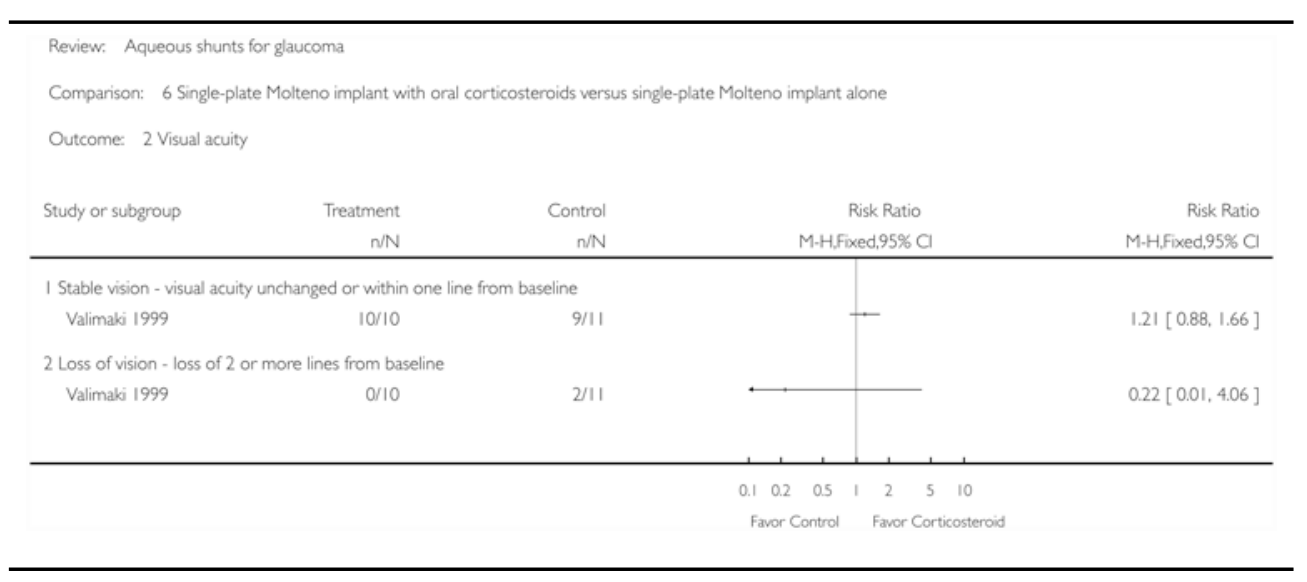

Analysis 6.3. Comparison 6 Single-plate Molteno implant with oral corticosteroids versus single-plate Molteno implant alone, Outcome 3 Anti-glaucoma medications

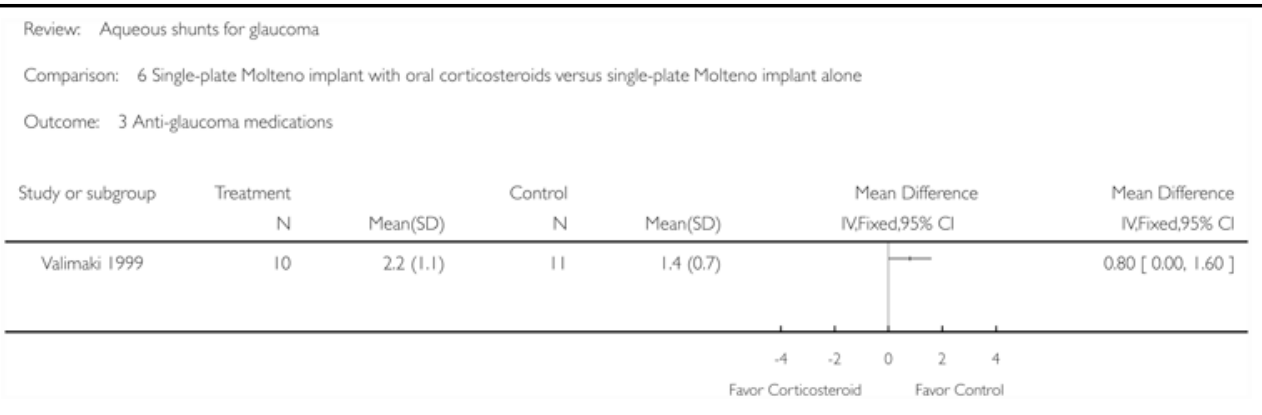


Analysis 7.1. Comparison 7 Double-plate Molteno implant + MMC versus Molteno implant + balanced salt solution (BSS), Outcome 1 Mean intraocular pressure at 12 months follow up

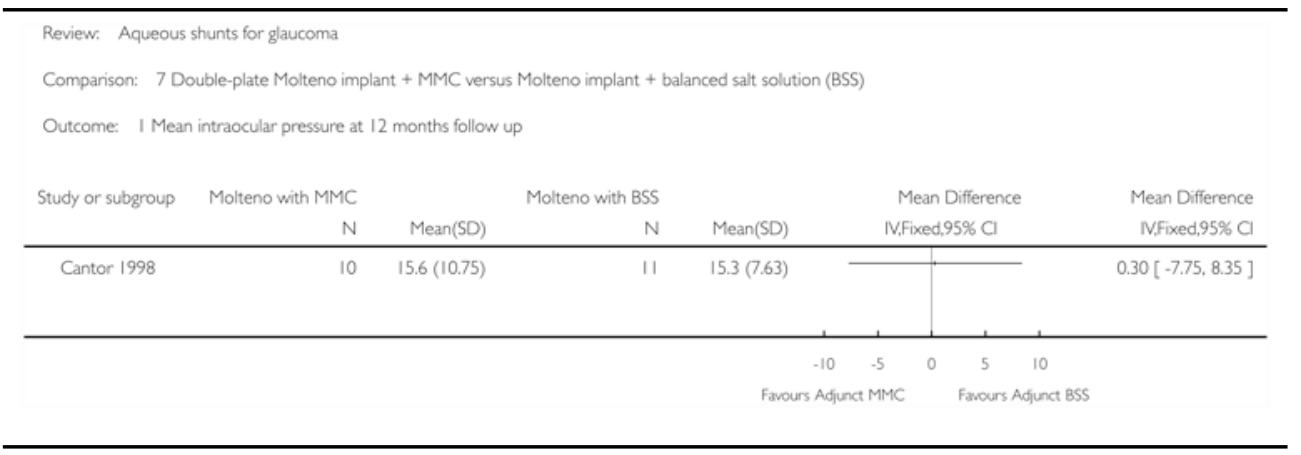

Analysis 7.2. Comparison 7 Double-plate Molteno implant + MMC versus Molteno implant + balanced salt solution (BSS), Outcome 2 Mean $\log$ MAR visual acuity at 12 months follow up

\begin{tabular}{|c|c|c|c|c|c|c|}
\hline \multicolumn{7}{|c|}{ Review. Aqueous shunts for glaucoma } \\
\hline \multicolumn{7}{|c|}{ Comparison: 7 Double-plate Molteno implant + MMC versus Molteno implant + balanced salt solution (BSS) } \\
\hline \multicolumn{7}{|c|}{ Outcome: 2 Mean logMAR visual acuity at 12 months follow up } \\
\hline \multirow[t]{2}{*}{ Study or subgroup } & Molteno with MMC & & Molteno with BSS & & Mean Difference & Mean Difference \\
\hline & N & Mean(SD) & $\mathrm{N}$ & $\operatorname{Mean}(S D)$ & IV,Fixed,95\% Cl & IV.Fixed,95\% Cl \\
\hline \multirow[t]{3}{*}{ Cantor 1998} & 10 & $1.5(1.26)$ & 11 & $2.1(1.66)$ & $\rightarrow$ & $-0.60[-1.85,0.65]$ \\
\hline & & & & & 0 & \\
\hline & & & & Favou & Fanours Ad & \\
\hline
\end{tabular}


Analysis 7.3. Comparison 7 Double-plate Molteno implant + MMC versus Molteno implant + balanced salt solution (BSS), Outcome 3 Anti-glaucoma medications at 12 months follow up

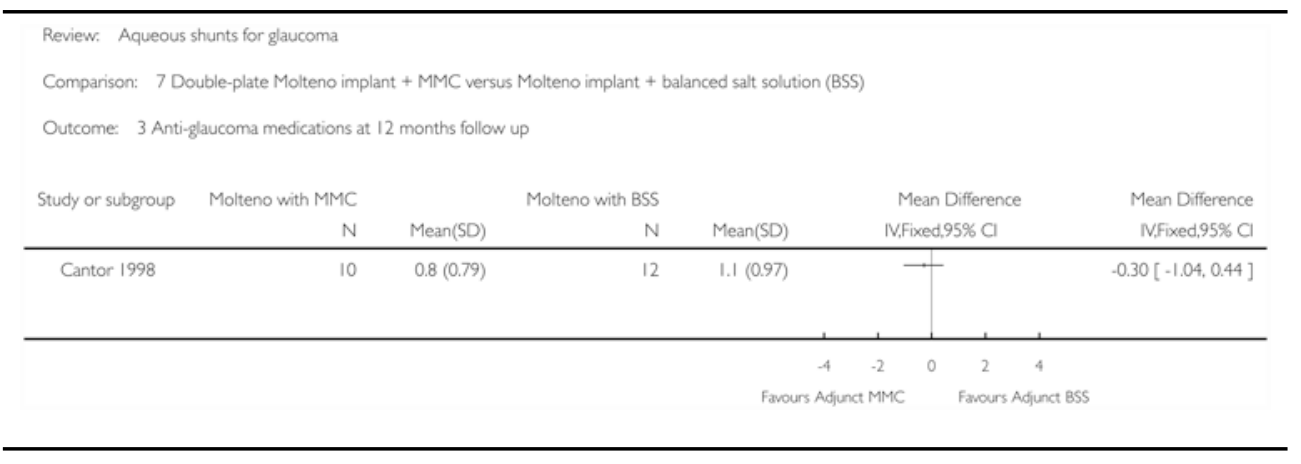

Analysis 8.1. Comparison 8 Single-plate Molteno implant versus double-plate Molteno implant, Outcome 1 IOP outcomes at final follow up

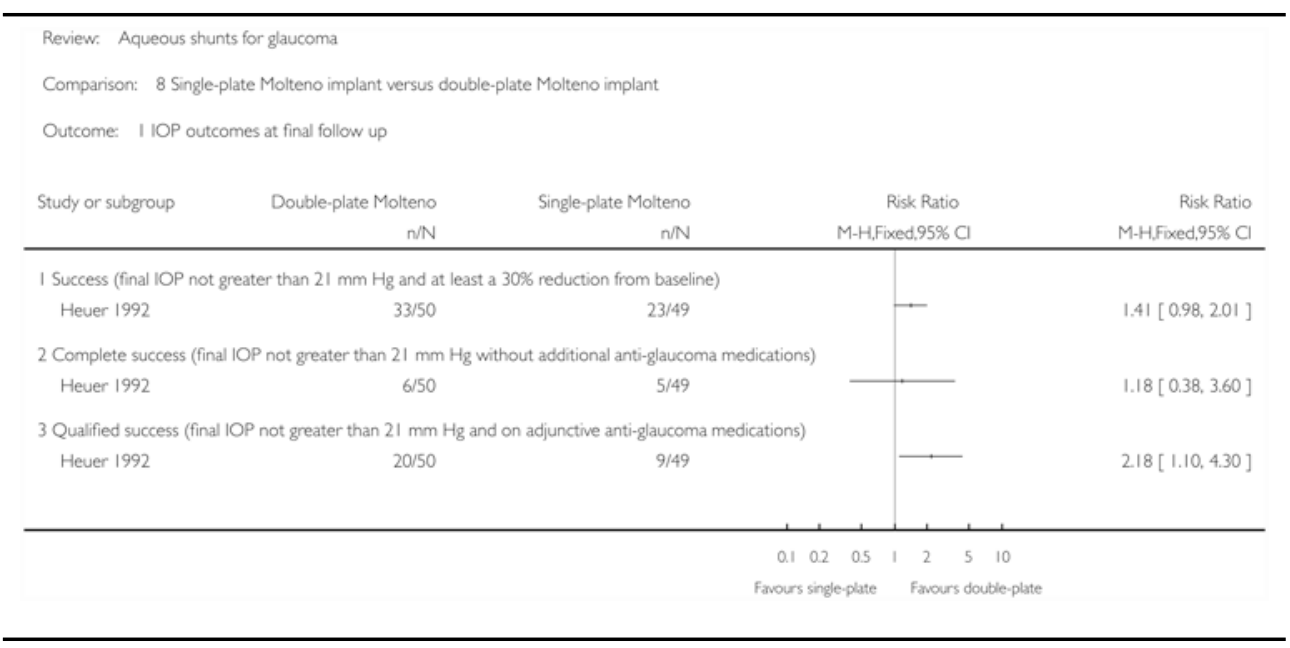


Analysis 9.1. Comparison $9350 \mathrm{~mm} 2$ Baerveldt implant versus 500 mm2 Baerveldt implant, Outcome 1 Mean intraocular pressure

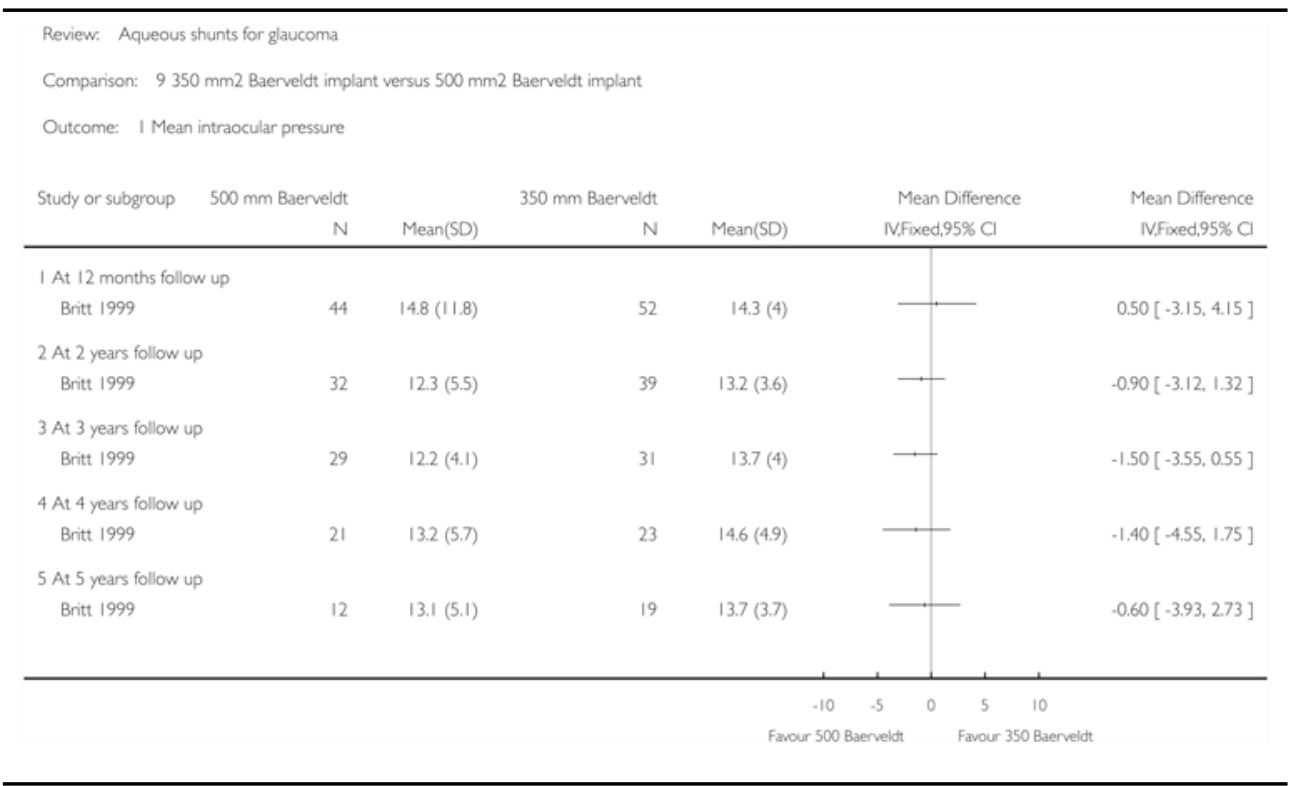

\title{
Appendix 1. CENTRAL and NRR search strategies
}

\author{
\#1 GLAUCOMA \\ \#2 INTRAOCULAR PRESSURE \\ \#3 CATARACT EXTRACTION \\ \#4 glaucoma* \\ \#5 (intraocular near pressur*) \\ \#6 (intra-ocular near pressur*) \\ \#7 (extract* or surg* or operat* or remov*) \\ \#8 cataract* \\ \#9 (\#7 and \#8) \\ $\# 10$ (\#1 or \#2 or \#3 or \#4 or \#5 or \#6 or \#9) \\ \#11 GLAUCOMA DRAINAGE IMPLANTS \\ \#12 MOLTENO IMPLANTS
}

\#13 (glaucom* and (molteno or ahmed or baerveldt or krupin or schocket or joseph or optimed or white or express))

\#14 (glaucom* and (tube* or devic* or drain* or shunt* or implant* or seton*)) 
$\# 15$ (\#11 or \#12 or \#13 or \#14)

\#16 (\#10 and \#15)

\title{
Appendix 2. MEDLINE and PubMed search strategies
}

\author{
\#1 explode "Glaucoma-" / all SUBHEADINGS in MIME,MJME \\ \#2 explode "Intraocular-Pressure" / all SUBHEADINGS in MIME,MJME \\ \#3 explode "Cataract-Extraction" / all SUBHEADINGS in MIME,MJME \\ \#4 ((glaucoma* or (intra?ocular near pressure)) in AB)or((glaucoma* or (intra?ocular \\ near pressure)) in TI) \\ \#5 (((extract* or surg* or operat* or remov*) near cataract*) in AB)or(((extract* or \\ surg* or operat* or remov*) near cataract*) in $\mathrm{TI}$ ) \\ \#6 \#1 or \#2 or \#3 or \#4 or \#5 \\ \#7 explode "Glaucoma-Drainage-Implants" / all SUBHEADINGS in MIME,MJME \\ \#8 explode "Molteno-Implants" / all SUBHEADINGS in MIME,MJME \\ \#9 ((Molteno or Ahmed or Baerveldt or Krupin or Schocket or Joseph or Optimed or \\ White or Express) in AB)or((Molteno or Ahmed or Baerveldt or Krupin or Schocket or \\ Joseph or Optimed or White or Express) in TI) \\ \#10 (((glaucoma*) near (tube* or devic* or drain* or shunt* or implant* or seton*)) in \\ AB)or(((glaucoma*) near (tube* or devic* or drain* or shunt* or implant* or seton*)) \\ in TI) \\ $\# 11$ \#7 or \#8 or \#9 or \#10 \\ \#12 \#6 and \#11
}

To identify randomized controlled trials, we combined this strategy with the Cochrane Highly Sensitive Search Strategy phases one and two as contained in the Cochrane Handbook for Systematic Reviews of Interventions (Higgins 2005a).

\section{Appendix 3. EMBASE search strategy}

\#1 exp GLAUCOMA/

\#2 exp Intraocular Pressure/

\#3 exp Cataract Extraction/

\#4 (glaucom\$ or ((intraocular or intra-ocular) adj3 pressur\$)).mp.

\#5 ((extract\$ or surg\$ or operat\$ or remov\$) adj3 cataract\$).mp.

\#6 ((extract\$ or surg\$ or operat\$ or remov\$) adj3 cataract\$).ab,ti.

$\# 7$ \#1 or \#2 or \#3 or \#4 or \#5 or \#6

\#8 exp Glaucoma Drainage Implant/ 
\#9 (Molteno or Ahmed or Baerveldt or Krupin or Schocket or Joseph or Optimed or White or Express).ab,ti.

\#10 (glaucom\$ adj5 (tube\$ or devic\$ or drain\$ or shunt\$ or implant\$ or seton)).ab,ti.

\#11 \#8 or \#9 or \#10

\#12 \#7 and \#11

To identify randomized controlled trials, we combined this strategy with the following strategy.

\#1 Randomized Controlled Trial/

\#2 exp Randomization/

\#3 Double Blind Procedure/

\#4 Single Blind Procedure/

\#5 random\$.ab,ti.

\#6 \#1 or \#2 or \#3 or \#4 or \#5

\#7 (animal or animal experiment).sh.

\#8 human.sh.

\#9 \#7 and \#8

\#10 \#7 not \#9

\#11 \#6 not \#10

\#12 Clinical Trial/

\#13 (clin\$ adj3 trial\$).ab,ti.

\#14 ((singl\$ or doubl\$ or trebl\$ or tripl\$) adj3 (blind\$ or mask\$)).ab,ti.

\#15 exp PLACEBO/

\#16 placebo\$.ab,ti.

\#17 random\$.ab,ti.

\#18 experimental design/

\#19 Crossover Procedure/

\#20 exp Control Group/

\#21 exp LATIN SQUARE DESIGN/

$\# 22 \# 12$ or \#13 or \#14 or \#15 or \#16 or \#17 or \#18 or \#19 or \#20 or \#21

\#23 \#22 not \#10

\#24 \#23 not \#11

\#25 exp Comparative Study/ 


\author{
\#26 exp Evaluation/ \\ \#27 exp Prospective Study/ \\ \#28 (control\$ or prospectiv\$ or volunteer\$).ab,ti. \\ $\# 29 \# 25$ or \#26 or \#27 or \#28 \\ \#30 \#29 not \#10 \\ \#31 \#30 not (\#11 or \#23) \\ \#32 \#11 or \#24 or \#31
}

\title{
Appendix 4. LILACS search terms
}

glaucoma\$ combined with the terms Molteno, Ahmed, Baerveldt, Krupin, Schocket, Optimed, ExPRESS, device\$, shunt\$, drainage, White pump shunt, Joseph valve or Joseph device

\section{References to studies included in this review}

*. Britt MT, LaBree LD, Lloyd MA, Minckler DS, Heuer DK, Baerveldt G, et al. Randomized clinical trial of the 350-mm2 versus the 500-mm2 Baerveldt implant: Longer term results. Is bigger better? Ophthalmology. 1999; 106:2312-8. [PubMed: 10599663]

Lloyd MA, Baerveldt G, Fellenbaum PS, Sidoti PA, Minckler DS, Martone JF, et al. Intermediate-term results of a randomized clinical trial of the $350-\mathrm{mm} 2$ versus $500-\mathrm{mm} 2$ Baerveldt implant. Ophthalmology. 1994; 101:1456-64. [PubMed: 8058290]

Cantor L, Burgoyne J, Sanders S, Bhavnani V, Hoop J, Brizendine E. The effect of mitomycin C on Molteno implant surgery: A 1-year randomized, masked, prospective study. Journal of Glaucoma. 1998; 7(4):240-6. [PubMed: 9713781]

Costa VP, Azuara-Blanco A, Netland PA, Lesk MR, Arcieri ES. Efficacy and safety of adjunctive mitomycin-C during Ahmed glaucoma valve implantation: A prospective randomized clinical trial. Ophthalmology. 2004; 111:1071-6. [PubMed: 15177955]

Duan X, Jiang Y, Qing G. Long-term follow-up study on Hunan aqueous drainage implantation combined with mitomycin-C for refractory glaucoma. Yan Ke Xue Bao Bian Ji Bu. 2003; 19(2):815 .

Gerber SL, Cantor LB, Sponsel WE. A comparison of postoperative complications from pressure-ridge Molteno implants versus Molteno implants with suture ligation. Ophthalmic Surgery and Lasers. 1997; 28:905-10. [PubMed: 9387176]

Heuer DK, Lloyd MA, Abrams DA, Baerveldt G, Minckler DS, Lee MB, Martone JF. Which is better? One or two? A randomized clinical trial of single-plate versus double-plate Molteno implantation for glaucomas in aphakia and pseudophakia. Ophthalmology. 1992; 99:1512-9. [PubMed: 1454316]

Hwang JM, Kee C. The effect of surface area expansion with pericardial membrane (Preclude) in Ahmed glaucoma valve implant surgery. Journal of Glaucoma. 2004; 13:335-9. [PubMed: 15226663]

Kee C. Prevention of early postoperative hypotony by partial ligation of silicone tube in Ahmed glaucoma valve implantation. Journal of Glaucoma. 2001; 10:466-9. [PubMed: 11740216]

Lima FE, Magacho L, Carvalho DM, Susanna R Jr, Avila MP. A prospective, comparative study between endoscopic cyclophotocoagulation and the Ahmed drainage implant in refractory glaucoma. Journal of Glaucoma. 2004; 13:233-7. [PubMed: 15118469]

Smith MF, Sherwood MB, McGorray SP. Comparison of the double-plate Molteno drainage implant with the Schocket procedure. Archives of Ophthalmology. 1992; 110:1246-50. [PubMed: 1520111] 
Susanna R Jr. Latin American Glaucoma Society (SLAG) Investigators. Partial Tenon's capsule resection with adjunctive mitomycin $\mathrm{C}$ in Ahmed glaucoma valve implant surgery. British Journal of Ophthalmology. 2003; 87:994-8. [PubMed: 12881343]

Valimaki J, Airaksinen PJ, Tuulonen A, Risteli J. Postoperative systemic corticosteroid treatment and Molteno implant surgery: A randomized clinical trial. Acta Ophthalmologica Scandinavica. 1999; 77:50-6. [PubMed: 10071149]

Wilson RP, Cantor L, Katz J, Schmidt CM, Steinmann WC, Allee S. Aqueous shunts: Molteno versus Schocket. Ophthalmology. 1992; 99:672-8. [PubMed: 1594210]

Wilson MR, Mendis U, Smith SD, Paliwal A. Ahmed glaucoma valve implant vs trabeculectomy in the surgical treatment of glaucoma: A randomized clinical trial. American Journal of Ophthalmology. 2000; 130:267-73. [PubMed: 11020403]

Wilson MR, Mendis U, Paliwal A, Haynatzka V. Long-term follow-up of primary glaucoma surgery with Ahmed glaucoma valve implant versus trabeculectomy. American Journal of Ophthalmology. 2003; 136:464-70. [PubMed: 12967799]

\section{References to studies excluded from this review}

Arroyave CP, Scott IU, Gedde SJ, Parrish RK II, Feuer WJ. Use of glaucoma drainage devices in the management of glaucoma associated with aniridia. American Journal of Ophthalmology. 2003; 135:155-9. [PubMed: 12566018]

Ayyala RS, Zurakowski D, Smith JA, Monshizadeh R, Netland PA, Richards DW, et al. A clinical study of the Ahmed glaucoma valve implant in advanced glaucoma. Ophthalmology. 1998; 105:1968-76. [PubMed: 9787371]

Ayyala RS, Zurakowski D, Monshizadeh R, Hong CH, Richards D, Layden WE, et al. Comparison of double-plate Molteno and Ahmed glaucoma valve in patients with advanced uncontrolled glaucoma. Ophthalmic Surgery and Lasers. 2002; 33:94-101. [PubMed: 11942556]

Beck AD, Freedman S, Kammer J, Jin J. Aqueous shunt devices compared with trabeculectomy with mitomycin-C for children in the first two years of life. American Journal of Ophthalmology. 2003; 136:994-1000. [PubMed: 14644208]

Benz MS, Scott IU, Flynn HW Jr, Gedde SJ. Retinal detachment in patients with a pre-existing glaucoma drainage device: Anatomic, visual acuity, and intraocular pressure outcomes. Retina. 2002; 22:283-7. [PubMed: 12055460]

Budenz DL, Scott IU, Nguyen QH, Feuer W, Singh K, Nicolela MT, et al. Combined Baerveldt glaucoma drainage implant and trabeculectomy with mitomycin-C for refractory glaucoma. Journal of Glaucoma. 2002; 11:439-45. [PubMed: 12362086]

Chen PP, Palmberg PF. Needling revision of glaucoma drainage device filtering blebs. Ophthalmology. 1997; 104:1004-10. [PubMed: 9186442]

Coleman AL, Hill R, Wilson MR, Choplin N, Kotas-Neumann R, Tam M, et al. Initial clinical experience with the Ahmed glaucoma valve implant. American Journal of Ophthalmology. 1995; 120:23-31. [PubMed: 7611326]

Coleman AL, Smyth RJ, Wilson MR, Tam M. Initial clinical experience with the Ahmed glaucoma valve implant in pediatric patients. Archives of Ophthalmology. 1997; 115:186-91. [PubMed: 9046253]

Djodeyre MR, Peralta Calvo J, Abelairras Gomez J. Clinical evaluation and risk factors of time to failure of Ahmed Glaucoma Valve implant in pediatric patients. Ophthalmology. 2001; 108:61420. [PubMed: 11237918]

Eid TE, Katz JL, Spaeth GL, Augsburger JJ. Tube-shunt surgery versus Neodymium:YAG cyclophotocoagulation in the management of neovascular glaucoma. Ophthalmology. 1997; 104:1692-700. [PubMed: 9331211]

Francis BA, Wang M, Lei H, Du LT, Minckler DS, Green RL, et al. Changes in axial length following trabeculectomy and glaucoma drainage device surgery. British Journal of Ophthalmology. 2005; 89(1):17-20. [PubMed: 15615739] 
Hill RA, Nguyen QH, Baerveldt G, Forster DJ, Rao NA, Heuer DK, et al. Trabeculectomy and Molteno implantation in the surgical treatment of uveitic glaucomas. American Academy of Ophthalmology. 1991; 108

Hill R, Ohanesian R, Voskanyan L, Malayan A. The Armenian Eye Care Project: surgical outcomes of complicated pediatric glaucoma. British Journal of Ophthalmology. 2003; 87:673-6. [PubMed: 12770958]

Hong CH, Arosemena A, Zurakowski D, Ayyala RS. Glaucoma drainage devices: a systematic review and current controversies. Survey of Ophthalmology. 2005; 50(1):48-60. [PubMed: 15621077]

Huang MC, Netland PA, Coleman AL, Siegner SW, Moster MR, Hill RA. Intermediate-term clinical experience with the Ahmed glaucoma valve implant. American Journal of Ophthalmology. 1999; 127:27-33. [PubMed: 9932995]

Kansal S, Moster MR, Gomes MC, Schmidt CM, Wilson RP. Patient comfort with combined anterior sub-Tenon's, topical and intracameral anesthesia versus retrobulbar anesthesia in trabeculectomy, phacotrabeculectomy, and aqueous shunt surgery. Ophthalmic Surgery and Lasers. 2002; 33:45662. [PubMed: 12449219]

The Krupin Eye Valve Filtering Surgery Study Group. Krupin eye valve with disk for filtration surgery. Ophthalmology. 1994; 101:651-8. [PubMed: 8152759]

Kim C, Kim Y, Choi S, Lee S, Ahn B. Clinical experienc of e-PTFE membrane implant surgery for refractory glaucoma. British Journal of Ophthalmology. 2003; 87:63-70. [PubMed: 12488265]

Lee D, Shin DH, Birt CM, Kim C, Kupin TH, Olivier MMG, et al. The effect of adjunctive mitomycin-C in Molteno implant surgery. Ophthalmology. 1997; 104:2126-35. [PubMed: 9400775]

Leuenberger EU, Grosskreutz CL, Walton DS, Pasquale LR. Advances in aqueous shunting procedures. International Ophthalmology Clinics. 1999; 39(1):139-53. [PubMed: 10083912]

Lloyd MA, Sedlak T, Heuer DK, Minckler DS, Baerveldt G, Lee MB, et al. Clinical experience with the single-plate Molteno implant in complicated glaucomas: Update of a pilot study. Ophthalmology. 1992; 99:679-87. [PubMed: 1594211]

Lloyd MA, Baerveldt G, Heuer DK, Minckler DS, Martone JF. Initial clinical experience with the Baerveldt implant in complicated glaucomas. Ophthalmology. 1994; 101:640-50. [PubMed: 8152758]

Luttrull JK, Avery RL. Pars plana implant and vitrectomy for treatment of neovascular glaucoma. Retina. 1995; 15:379-87. [PubMed: 8594629]

Minckler D. Advances with aqueous shunts. Journal of Glaucoma. 2001; 10(5 Supplement):S85-7. [PubMed: 11890289]

Molteno ACB. New implant for drainage in glaucoma: Clinical trial. British Journal of Ophthalmology. 1969; 53:606-15. [PubMed: 4900144]

Molteno ACB, Sayawat N, Herbison P. Otago glaucoma surgery outcome study: Long-term results of uveitis with secondary glaucoma drained by Molteno implants. Ophthalmology. 2001; 108:60513. [PubMed: 11237917]

Molteno ACB, Bevin TH, Herbison P, Houliston MJ. Otago glaucoma surgery outcome study: Longterm follow-up of cases of primary glaucoma with additional risk factors drained by Molteno implants. Ophthalmology. 2001; 108:2193-200. [PubMed: 11733258]

Morad Y, Donaldson CE, Kim YM, Abdolell M, Levin AV. The Ahmed drainage implant in the treatment of pediatric glaucoma. American Journal of Ophthalmology. 2003; 135:821-9. [PubMed: 12788122]

Noureddin BN, Wilson-Holt N, Lavin M, Jeffrey M, Hitchings RA. Advanced uncontrolled glaucoma: Nd: YAG cyclophotocoagulation or tube surgery. Ophthalmology. 1992; 99:430-7. [PubMed: 1565456]

Nouri-Madhavi K, Caprioli J. Evaluation of the hypertensive phase after insertion of the Ahmed glaucoma valve. American Journal of Ophthalmology. 2003; 136:1001-8. [PubMed: 14644209]

Pastor SA, Singh K, Lee DA, Juzych MS, Lin SC, Netland PA, et al. Cyclophotocoagulation: A report by the American Academy of Ophthalmology. Ophthalmology. 2001; 108:2130-8. [PubMed: 11713091] 
Paysse E, Lee PL, Lloyd MA, Sidoti PA, Fellenbaum PS, Baerveldt G, et al. Suprachoroidal hemorrhage after Molteno implantation. Journal of Glaucoma. 1996; 5:170-5. [PubMed: 8795754]

Perkins TW, Cardakli UF, Eisele JR, Kaufman PL, Heatley GA. Adjunctive mitomycin-C in Molteno implant surgery. Ophthalmology. 1995; 102:91-7. [PubMed: 7831048]

Perkins TW, Gangnon R, Ladd W, Kaufman PL, Libby CM. Molteno implant with mitomycin-C: Intermediate-term results. Journal of Glaucoma. 1998; 7:86-92. [PubMed: 9559493]

Rapuano CJ, Schmidt CM, Cohen EJ, Rajpal RK, Raber IM, Katz JL, et al. Results of alloplastic tube shunt procedures before, during, or after penetrating keratoplasty. Cornea. 1995; 14(1):26-32. [PubMed: 7712732]

Saw SM, Gazzard G, Friedman DS. Interventions for angle-closure glaucoma: An evidence-based update. Ophthalmology. 2003; 110:1869-79. [PubMed: 14522756]

Sayyad FE, Helal M, Elsherif Z, El-Maghraby A. Molteno implant versus trabeculectomy with adjunctive intraoperative mitomycin-C in high risk glaucoma patients. Journal of Glaucoma. 1995; 4:80-5. [PubMed: 19920650]

Seah SKL, Gazzard G, Aung T. Intermediate-term outcome of Baerveldt glaucoma implants in Asian eyes. Ophthalmology. 2003; 110:888-94. [PubMed: 12750085]

Shaikh S, Goldblum RS, Morse LS, Aslam R, Singh K. Setons and serum IgG titers to silicone. Journal of Glaucoma. 2002; 11:508-10. [PubMed: 12483096]

Sivak-Callcott JA, O'Day DM, Gass DM, Tsai JC. Evidence-based recommendations for the diagnosis and treatment of neovascular glaucoma. Ophthalmology. 2001; 108:1767-78. [PubMed: 11581047]

Strum J, Postelmans L, Deflorenne C, Huyghe P, Libert J. The Baerveldt implant in refractory glaucoma: clinial results [Implant de Baerveldt dans les glaucomes refractaires: resultats cliniques]. Bulletin de la Societe Belge d' Ophthalmologie. 1998; 267:169-74.

Taglia DP, Perkins TW. Permanent ligation of double-plate Molteno implant distal tube to control hypotony. Archives of Ophthalmology. 1999; 117(9):1244-5. [PubMed: 10496401]

Toupouzis F, Coleman AL, Choplin N, Bethlem MM, Hill R, Yu F, et al. Follow-up of the original cohort with the Ahmed glaucoma valve implant. American Journal of Ophthalmology. 1999; 128:198-204. [PubMed: 10458176]

Tsai JC, Johnson CC, Dietrich MS. The Ahmed shunt versus the Baerveldt shunt for refractory glaucoma: A single-surgeon comparison of outcome. Ophthalmology. 2003; 110:1814-21. [PubMed: 13129882]

Tuli SS, WuDunn D, Ciulla TA, Cantor LB. Delayed suprachoroidal hemorrhage after glaucoma filtration procedures. Ophthalmology. 2001; 108:1808-11. [PubMed: 11581053]

Whittaker KW, Molteno ACB, Bevin TH. Otago Glaucoma Surgery Outcome Study. Atypical late failure of drainage following clear cornea trabeculectomy. Clinical and Experimental Ophthalmology. 2003; 31:129-32. [PubMed: 12648046]

\section{References to studies awaiting assessment}

Allan, B. Advanced Glaucoma Filtration Implant Development. Moorfields Eye Hospital, NHS Foundation Trust; 1996. The role of biomaterials in glaucoma treatment.

Chalam KV, Lin N, Tripathi R. Advanced neovascular glaucoma: Pars plana modified Baerveldt implant versus Nd:Yag transscleral cyclophotocoagulation. American Academy of Ophthalmology. 1999; 241

Chalam KV, Malkani SM, Tripathi RC, Ambati J. Neovascular glaucoma: pars plana Baerveldt implant vs Nd: Yag transscleral cyclophotocoagulation vs Yag endocyclophotocoagulation. American Academy of Ophthalmology. 2001; 168

Chen PC, Schuman JS, Mattox C, Weiss HS, Krug JH Jr, Gross FJ. A randomized prospective clinical trial comparing surface-modified with standard Krupin valves with disk. American Academy of Ophthalmology. 1998; 150

Chihara E, Kubota H, Takanashi T, Nao-i N. Outcome of White pump shunt surgery for neovascular glaucoma in Asians. Ophthalmic Surgery and Lasers. 1992; 23(10):666-71. 
Chua JKH, Poon ASY, Tham CCY, Lai JS, Lam DSC. Efficacy and safety of adjunctive mitomycin-C in Ahmed glaucoma valve implant surgery. American Academy of Ophthalmology. 2002; 257

Kumaz E, Kubaloglu A, Yilmaz Y, Koytak A, Ozerturk Y. The effect of adjunctive mitomycin-C in Ahmed glaucoma valve implantation. European Journal of Ophthalmology. 2005; 15(1):27-31. [PubMed: 15751236]

Liu Y, Li H, Chen J. Shunt tube implantation combining amniotic membrane transplantation and implantation of Molteno implant for glaucoma after penetrating keratoplasty. Yan Ke Xue Bao Bian Ji Bu. 2000; 16(2):65-72.

Prywes AS, Marcus C, Boyman A, Udell I. Graft survival in combined Ahmed glaucoma valve implant and penetrating keratoplasty. American Academy of Ophthalmology. 1999; 184

Yablonski ME. Trabeculectomy with internal tube shunt: a novel glaucoma surgery. Journal of Glaucoma. 2005; 14(2):91-7. [PubMed: 15741807]

\section{References to ongoing studies}

Gedde SJ, Schiffman JC, Feuer WJ, Parrish RK 2nd, Heuer DK, Brandt JD, et al. The Tube Versus Trabeculectomy Study: design and baseline characteristics of study patients. American Journal of Ophthalmology. 2005; 140(2):275-87. [PubMed: 16086949]

\section{Additional references}

ANSI Z8027. American National Standard for Ophthalmics Aqueous Shunts for Glaucoma Application. American Optometrics Association; 1998.

Chalam KV, Gandham S, Gupta S, Tripathi BJ, Tripathi RC. Pars plana modified Baerveldt implant versus neodymium: YAG cyclophotocoagulation in the management of neovascular glaucoma. Ophthalmic Surgery and Lasers. 2002; 33:383-93. [PubMed: 12358292]

Deeks, JJ.; Higgins, JPT.; Altman, DG.; Higgins, JPT.; Green, S., editors. The Cochrane Library. John Wiley \& Sons, Ltd; Chichester, UK: 2005. Analysing and presenting results. Cochrane Handbook for Systematic Reviews of Interventions 4.2.5. [updated May 2005] Section 8

The Fluorouracil Filtering Surgery Study Group. Five-year follow-up of the fluorouracil filtering surgery study. American Journal of Ophthalmology. 1996; 121:349-66. [PubMed: 8604728]

Gandolfi S, Traverso CF, Bron A, Sellem E, Kaplan-Messas A, Belkin M. Short-term results of a miniature draining implant for glaucoma in combined surgery with phacoemulsification. Acta Ophthalmologica Scandinavica. 2002; 236 Suppl:66. [PubMed: 12390153]

Higgins, JPT.; Green, S., editors. The Cochrane Library. John Wiley \& Sons, Ltd; Chichester, UK: 2005. Cochrane Handbook for Systematic Reviews of Interventions 4.2.5. updated May 2005

Higgins, JPT.; Green, S., editors. The Cochrane Library. John Wiley \& Sons, Ltd; Chichester, UK: 2005. Assessing study quality. Cochrane Handbook for Systematic Reviews of Interventions 4.2.5. [updated May 2005] Section 6

Hoffman KB, Feldman RM, Budenz DL, Gedde JS, Chacra GA, Schiffman JC. Combined cataract extraction and Baerveldt glaucoma drainage implant: indications and outcomes. Ophthalmology. 2002; 109:1916-20. [PubMed: 12359614]

Lloyd MA, Heuer DK, Baerveldt G, Minckler DS, Martone JF, Lean JS, et al. Combined Molteno implantation and pars plana vitrectomy for neovascular glaucomas. Ophthalmology. 1991; 98(9): 1401-5. [PubMed: 1945316]

Mills RP, Reynolds A, Emond MJ, Barlow WE, Leen MM. Long-term survival of Molteno glaucoma drainage devices. Ophthalmology. 1996; 103:299-305. [PubMed: 8594518]

Minckler DS, Heuer DK, Hasty B, Baerveldt G, Cutting RC, Barlow WE. Clinical experience with the single-plate Molteno implant in complicated glaucomas. Ophthalmology. 1998; 95:1181-8. [PubMed: 3211496]

Minckler, DS. 100 Years of Progress in Glaucoma. Vol. Ch 19. Philadelphia: Lippincott-Raven; 1997. Glaucoma drainage devices, horsehair to silicone. American Academy of Ophthalmology Glaucoma Day Symposium, Chicago, Illinois, October 1996; p. 287-92. 
Molteno ACB. The optimal design of drainage implants for glaucoma. Transactions of the Ophthalmological Society of New Zealand. 1981; 33:29-41.

Molteno AC, Bevin TH, Herbison P, Houliston MJ. Otago glaucoma surgery outcome study: longterm follow-up of cases of primary glaucoma with additional risk factors drained by Molteno implants. Ophthalmology. 2001; 108:2193-200. [PubMed: 11733258]

Molteno AC, Fucik M, Dempster AG, Bevin TH. Otago glaucoma surgery outcome study: factors controlling capsule fibrosis around Molteno implants with histopathological correlation. Ophthalmology. 2003; 110:2198-206. [PubMed: 14597530]

Prata JA Jr, Mermoud A, LaBree L, Minckler DS. In vitro and In vivo flow characteristics of glaucoma drainage implants. Ophthalmology. 1995; 102:894-904. [PubMed: 7777296]

Prata JA Jr, Santos RCR, LaBree L, Minckler DS. Surface area of glaucoma implants and perfusion flow rates in rabbit eyes. Glaucoma. 1995; 4:274-80.

Prata JA Jr, Minckler DS, Mermoud A, Baerveldt G. Effects of mitomycin-C on the function of Baerveldt glaucoma drainage implants in rabbits. Glaucoma. 1996; 5:29-38.

Schocket SS, Lakhanpal V, Richards RD. Anterior chamber tube shunt to an encircling band in the treatment of neovascular glaucoma. Ophthalmology. 1982; 89:1188-94. [PubMed: 6185900]

Sidoti PA, Minckler DS, Baerveldt G, Lee PP, Heuer DK. Aqueous tube shunt to a pre-existing episcleral encircling element in the treatment of complicated glaucomas. Ophthalmology. 1994; 101:1036-43. [PubMed: 8008344] 


\section{Plain Language Summary}

\section{Aqueous shunts for glaucoma}

Glaucoma is a leading cause of blindness worldwide. Treatments for glaucoma include the use of eye drops, laser treatment, and a variety of surgical operations. Surgery is usually considered only after eye drops and lasers have proven to be ineffective. Among surgical operations, aqueous shunts or glaucoma drainage devices which come in a variety of sizes and shapes are often used in complicated cases when traditional types of surgery such as trabeculectomy (making a cleft in the eye wall) have not worked. The typical aqueous shunt includes a tiny rubber tube (drain) that connects the eye fluid chamber to a plate that is attached to the eye wall. The plate or explant stimulates the formation by the body of a space into which eye fluid can drain. This review summarizes previously published randomized and quasi-randomized controlled trial results for aqueous shunts (studies that compare treatment with no treatment or to alternative treatments including a control group). We included 15 trials involving 1153 participants with varied diagnoses of glaucoma. At present there is insufficient evidence to conclude that clinical outcomes of trabeculectomy differ substantially from those of aqueous shunts in similar patients with complicated glaucomas. There is also insufficient evidence to conclude that any specific aqueous shunt is superior to the others currently in widespread use. 
Table 1

Interventions evaluated in trials included in this review

\begin{tabular}{|c|c|c|}
\hline Comparison & Author Year & No. eyes exp/control \\
\hline Ahmed implant versus trabeculectomy & Wilson 2000 & $55 / 62$ \\
\hline Ahmed implant versus trabeculectomy & Wilson 2003 & $59 / 64$ \\
\hline Ahmed implant with and without partial resection of Tenon's capsule & Susanna 2003 & $45 / 47$ \\
\hline Ahmed implant with and without partial ligation of tube & Kee 2001 & $16 / 16$ \\
\hline Ahmed implant with Mitomycin C versus Ahmed implant with balanced salt solution & Costa 2004 & $34 / 26$ \\
\hline Ahmed implant with and without pericardial surface expansion & Hwang 2004 & $10 / 10$ \\
\hline Ahmed implant versus endocyclophotocoagulation & Lima 2004 & $34 / 34$ \\
\hline $500 \mathrm{~mm}$ Baerveldt versus $350 \mathrm{~mm}$ Baerveldt & Britt 1999 & $52 / 55$ \\
\hline $\begin{array}{l}\text { Double-plate pressure-ridge Molteno implant with Mitomycin C versus Molteno implant } \\
\text { with balanced salt solution }\end{array}$ & Cantor 1998 & $12 / 13$ \\
\hline Single-plate Molteno implant versus double-plate Molteno implant & Heuer 1992 & $66 / 66$ \\
\hline Double-plate Molteno implant versus Schocket shunt & Smith 1992 & $19 / 21$ \\
\hline Double-plate Molteno implant versus Schocket shunt & Wilson 1992 & 134 (allocation not reported) \\
\hline $\begin{array}{l}\text { Double-plate pressure-ridge Molteno implant versus standard double-plate Molteno implant } \\
\text { with tube ligature }\end{array}$ & Gerber 1997 & $15 / 15$ \\
\hline Single-plate Molteno implant with and without postoperative oral corticosteroids & Valimaki 1999 & $11 / 11$ \\
\hline Hunan aqueous device with and without Mitomycin C & Duan 2003 & $65 / 94$ \\
\hline
\end{tabular}



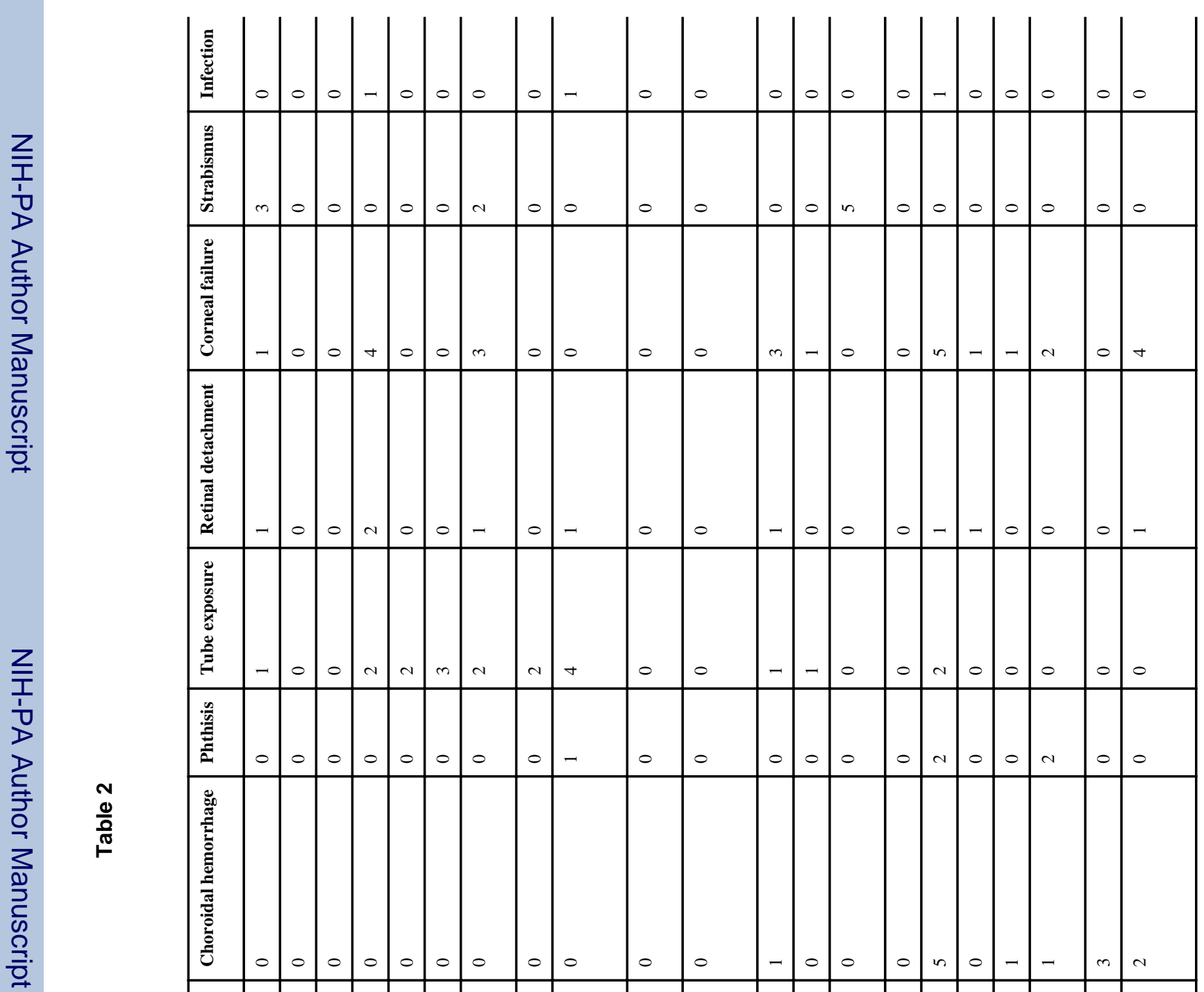

\begin{tabular}{|c|c|c|c|c|c|c|c|c|c|c|c|c|c|c|c|c|c|c|c|c|c|}
\hline 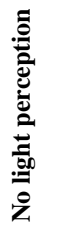 & 0 & 0 & 0 & 0 & 0 & 0 & 0 & $\begin{array}{l}\frac{3}{0} \\
\frac{0}{2} \\
\text { D } \\
\text { n. }\end{array}$ & 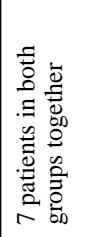 & 0 & 0 & 0 & 0 & 0 & 0 & 0 & 0 & 0 & $N$ & 0 & 0 \\
\hline 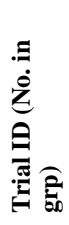 & 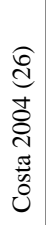 & 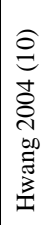 & 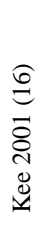 & 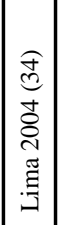 & $\begin{array}{l}0 \\
0 \\
8 \\
8 \\
0 \\
0 \\
0 \\
0 \\
3\end{array}$ & 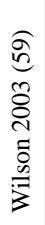 & 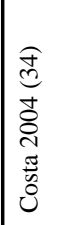 & 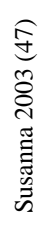 & 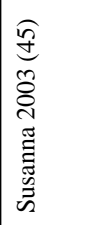 & 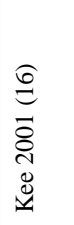 & 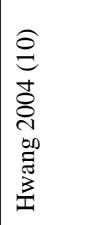 & 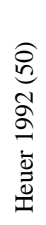 & 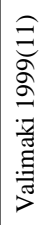 & 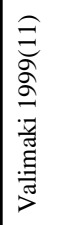 & 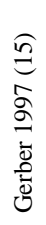 & 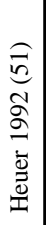 & 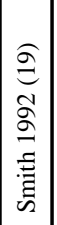 & 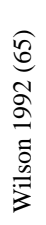 & 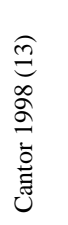 & 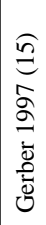 & 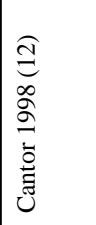 \\
\hline 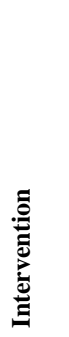 & 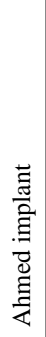 & & & & & & 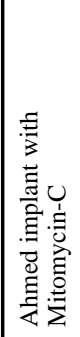 & & 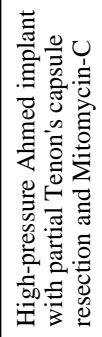 & 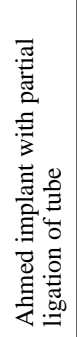 & 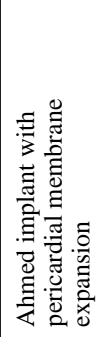 & 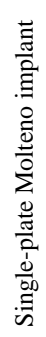 & & 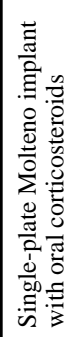 & 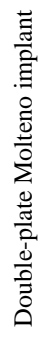 & & & & 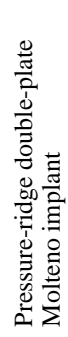 & & 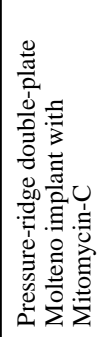 \\
\hline
\end{tabular}

Cochrane Database Syst Rev. Author manuscript; available in PMC 2015 January 13. 


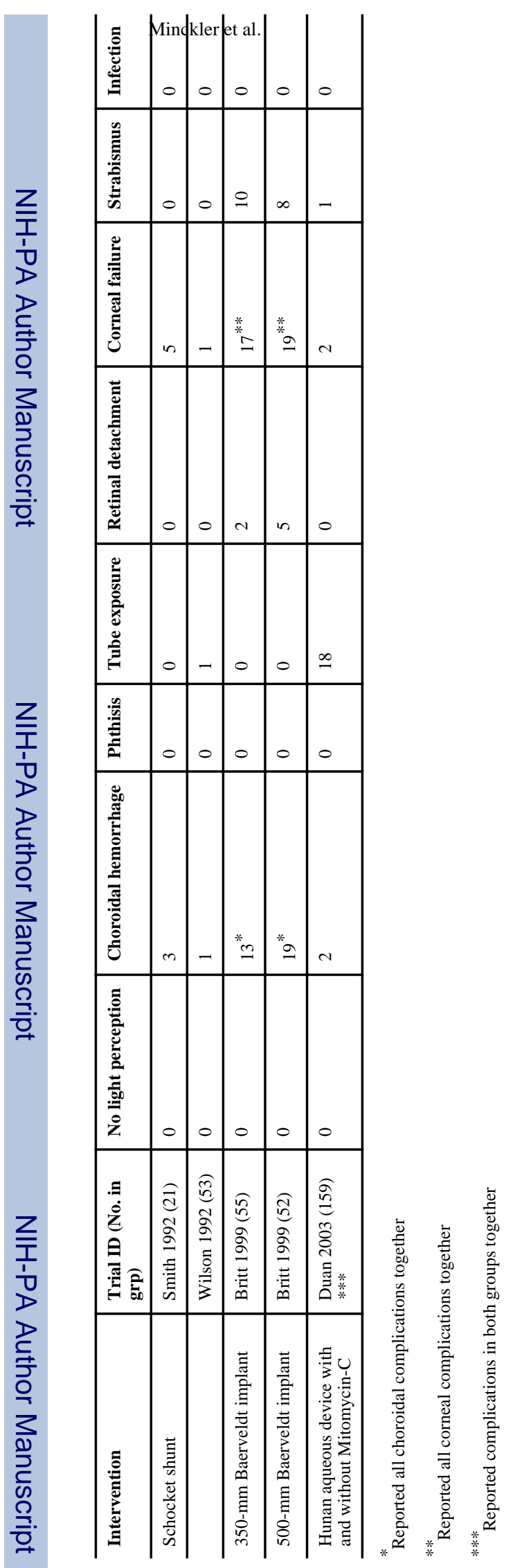

Page 54 